\title{
Synthesis of Ni-based catalysts by hexamethylenetetramine-nitrates solution combustion method for co-production of hydrogen and nanofibrous carbon from methane
}

\author{
D.G. Kuvshinov","*, P.B. Kurmashov ${ }^{\mathrm{b}}$, A.G. Bannov ${ }^{\mathrm{b}}$, M.B. Popov ${ }^{\mathrm{b}}$, G.G. Kuvshinov \\ ${ }^{a}$ Department of Chemical Engineering, University Hull, Cottingham road, HU6 7RX, UK \\ d.kuvshinov@hull.ac.uk \\ bNovosibirsk State Technical University, Russia \\ ${ }^{c}$ Sochi State University, Russia
}

\begin{abstract}
It was shown that hexamethylenetetramine (HMT) is a new effective fuel for single-step solutions combustion synthesis (SCS) of supported Ni catalysts for methane decomposition into hydrogen and nanofibrous carbon. Several generalized chemical equations reflecting different ideas about combustion of the $\mathrm{HMT}-\mathrm{Ni}\left(\mathrm{NO}_{3}\right)_{2}-\mathrm{Cu}\left(\mathrm{NO}_{3}\right)_{2}-\mathrm{Al}\left(\mathrm{NO}_{3}\right)_{3}-\mathrm{H}_{2} \mathrm{O}$ system have been derived. On the basis of those equations the adiabatic combustion temperature $\left(T_{a d}\right)$ and the amount of gaseous products $\left(n_{g}\right)$ have been calculated depending on the ignition temperature $\left(T_{1}\right)$, water content $(m)$, excess fuel coefficient $(\varphi)$, and the composition of the obtained solid product. The calculations have shown that $T_{a d}$, depending on $m$ and $\varphi$, changes from hundreds to thousands of degrees Kelvin. Increase of $\mathrm{Al}_{2} \mathrm{O}_{3}$ content in the catalyst up to 0.6 increases $\mathrm{T}_{a d}$ by hundreds of degrees, and that increase of the Ni:NiO ratio up to 0.5 lowers $T_{a d}$ by tens of degrees. Three samples of the supported unreduced $0.97 \mathrm{NiO} / 0.03 \mathrm{Al}_{2} \mathrm{O}_{3}$ catalyst were successfully prepared with the help of the SCS method using HMT as the fuel at $\varphi=0.7$. Those samples, obtained at reaction mixture preliminary heating rates $\mathrm{V}=1,10,15 \mathrm{~K} / \mathrm{min}$ were characterised using XRD, TEM, and $\mathrm{SEM}$, and further tested in a pure methane decomposition reaction $\left(100 \mathrm{~L}_{\mathrm{CH} 4} / \mathrm{h} / \mathrm{g}_{\mathrm{cat}}, 823 \mathrm{~K}, 1 \mathrm{bar}\right)$. Nanoparticles of metal $\mathrm{Ni}$ were found in the SCS products, in contrast to cases when other types of fuel were used with $\varphi<1$. The experimental results showed that the higher is $\mathrm{V}$, the higher is the maximum SCS temperature, the larger is the average size of Ni nanoparticles in unreduced catalyst, the higher is the stability of unreduced catalyst (up to $14 \mathrm{~h}$ ) and the higher is the specific yield of hydrogen (up to $818 \mathrm{~mol} / \mathrm{mol}_{\text {cat }}$ ) during the deactivation period. The activity value of our unreduced catalyst $\left(0.7 \mathrm{~mol} / \mathrm{h} / \mathrm{g}_{\mathrm{cat}}\right)$ in the methane decomposition reaction is close to maximum activity values of pre-reduced Ni catalysts of different nature reported in published articles.
\end{abstract}

Key Words: nickel-based catalyst, solution combustion synthesis, hexamethylenetetramine, adiabatic combustion, methane decomposition, hydrogen and carbon nanofibers production.

\section{Introduction}

The catalytic decomposition of hydrocarbons to hydrogen and carbon $\left(C_{n} H_{m} \rightarrow n C+\right.$ $\frac{1}{2} m H_{2}, \Delta H_{R}^{0}$ is hydrocarbon dependent, $\left.\Delta H_{R_{-} C H 4}^{0}=75,6 \frac{\mathrm{kJ}}{\mathrm{mol}}\right)$ is currently considered as the basis of efficient technologies for hydrogen production [1]. The advantages of this process, compared to its alternatives, are ecological friendliness, simplicity and the lack of carbon oxides in the reaction products. Furthermore, the use of co-produced nanostructured carbon as a market valuable by-product allows to reduce the cost of the hydrogen production. 
It is known that industrial approach for hydrogen production based on the hydrocarbons catalytic decomposition is limited due to the fact of relatively fast deactivation of applied catalysts mainly by deposited carbons. The introduction of additional steps in order to activate the catalyst via oxidation or hydrogenation of the deposited carbon negates the stated advantages. Hence the reduction of the catalyst production cost and as the second option the hydrogen cost compensation via high yield of valuable nanocarbons are currently accepted as one of the main options for the advancement of such technologies.

One of the proposed solutions [2] is to use cheap carbon materials as the catalyst so no purification is required for the produced carbons. However, the consumer properties of such carbon products are dissatisfactory. The second option is to produce hydrogen and new unique carbon nanomaterials by the hydrocarbons decomposition in presence of catalysts containing certain metals of $4^{\text {th }}$ period of Periodic Table $[3,4]$. These materials consisting mainly of carbon nanofibers (CNFs) and carbon nanotubes (CNTs) have various morphologies, different structural and textural features as well as different physical, chemical and catalytic properties. It has been shown that the characteristics of these materials can vary due to their synthesis conditions. CNF materials can be produced in a form of mesoporous granules [5]. Their application fields include energetics [6], catalysis [7,8], adsorption purification [9,10], immobilization of biologically active substances [11], carbon-polymer composite technologies [12,13] and other applications.

For the first time the technological concept of co-production of hydrogen and carbon nanomaterials by decomposition of hydrocarbons on special metal catalysts was proposed and implemented at the pilot reactor level by G. Kuvshinov et.al. [3,14-16]. The current state of research in this field is reviewed $[4,17,18]$. It was shown that the catalyst's efficiency remains one of the key issues for the successful commercial technology implementation.

The main catalytic systems and methods of the catalyst preparation for the process of carbon nanostructures synthesis by hydrocarbon's decomposition are well outlined [19]. During the supported catalysts preparation, the active phase in the form of metal or alloy nanoparticles is typically obtained by reducing the corresponding metal oxides with hydrogen [20]. The catalyst precursor containing the active phases in the form of oxides will be hereinafter referred to as the unreduced catalyst. Normally the transition metals of $4^{\text {th }}$ period, such as $\mathrm{Ni}, \mathrm{Co}, \mathrm{Fe}$ as well as their alloys and alloys with other metals for example copper and molybdenum, are used as the active phase due to carbon's high solubility within them. The hard-reducible oxides $\mathrm{Al}_{2} \mathrm{O}_{3}, \mathrm{SiO}_{2}, \mathrm{MgO}$, $\mathrm{ZrO}_{2}$ etc. or carbon are used as the catalyst supporters. It was shown that the levels of catalyst activity and stability in the course of methane decomposition depend significantly on chemical composition and structural characteristics of the carrier $[21,22]$. There were reports about preparation of unsupported porous $\mathrm{NiO}$-catalysts on which carbon was deposited in the form of nanograins [23]. Since the catalyst become deactivated relatively quickly, its integral efficiency is evaluated by the specific yield of hydrogen $\left(y_{H}, \mathrm{~mol} / \mathrm{mol}_{\text {cat }}\right.$ or $\left.\mathrm{mol} / \mathrm{g}_{\text {cat }}\right)$ and carbon $\left(y_{c}, \mathrm{~mol} \mathrm{~mol}_{\text {cat }}\right.$ or $\left.\mathrm{g} / \mathrm{g}_{\text {cat }}\right)$ during the deactivation period.

Supported catalysts with high active component content (>30 wt.\%) produce the highest specific yield of hydrogen and carbon [24]. The specific yields and properties of the synthesized carbon nanostructures depend primarily on the size, shape and state of the metallic nanoparticles [25], as well as on the interaction between them and the supporter [26]. It has been noted that for the reaction temperatures of $500{ }^{\circ} \mathrm{C}, 550{ }^{\circ} \mathrm{C}, 580{ }^{\circ} \mathrm{C}$ and $700{ }^{\circ} \mathrm{C}$ the optimal sizes of metallic nanoparticles in Ni-based supported catalysts are $60-100 \mathrm{~nm}, 30-40 \mathrm{~nm}, 34 \mathrm{~nm}$, and 10-20 nm respectively [27]. With other parameters being constant, the maximum value of the product's 
specific yield depends on the active phase content and the ratio between the contents of the first and second metals if the catalyst is bimetallic [20,28,29].

The supported catalysts, with a high active component content, may be arranged in the following order, depending on the maximum achieved specific yield of the products [17]:

$$
(\mathrm{Pd}+\mathrm{Ni})>(\mathrm{Ni}+\mathrm{Cu})>\mathrm{Ni}>(\mathrm{Fe}+\mathrm{Co})=(\mathrm{Fe}+\mathrm{Ni})>\mathrm{Co}>\mathrm{Fe} .
$$

Therefore, the supported nickel and nickel-copper catalysts, when not considering catalysts based on precious metals, show the most promise for the use in large-scale co-production technology.

There are many known methods for preparing metallic catalysts for the processes of decomposition of hydrocarbons into hydrogen and carbon nanomaterials [19]. A few most often used methods of supported catalyst preparation are co-precipitation [27,29], impregnation [30], sol-gel synthesis [24,31] mechanochemical activation [32] and solution combustion synthesis (SCS) [33,34].

The SCS was first proposed by J. Kingsley and K. Patil [35] as a method for obtaining highly dispersed alumina and similar oxide systems in one step. The aluminium nitrate hydrate $\mathrm{Al}\left(\mathrm{NO}_{3}\right)_{3} * 9 \mathrm{H}_{2} \mathrm{O}$ (oxidiser) and urea $\mathrm{CH}_{4} \mathrm{~N}_{2} \mathrm{O}$ (fuel) were mixed in a stoichiometric ratio and dissolved in a minimal amount of water. The resulting paste-like mixture was placed in a muffle furnace at the temperature around $500{ }^{\circ} \mathrm{C}$, where the paste spontaneously ignited as the flame temperature increased to $1600{ }^{\circ} \mathrm{C}$. As the result, a large number of gaseous products and a solidstate residue in the form of nanocrystallite $\mathrm{Al}_{2} \mathrm{O}_{3}$ foam were obtained. The duration of the process was around 5 minutes, with the flame combusting period of 2 minutes. Reviews [36-38] provide the information on the state of research in the field of SCS, including catalysts preparation.

The solutions for SCS contain a solvent (usually water) and one or more oxidizers, which simultaneously act as a precursor of a metal oxide (usually the corresponding metal nitrate) and one or more kinds of fuel performing the role of a chelating agent (typically linear and cyclic organic amines, acids and amino acids) [38-40]. The most commonly used fuels are industrially produced urea, glycine, citric acid, hexamethylenetetramine (HMT) and laboratory-prepared hydrazine-based agents [39-41]. The type of fuel used has a significant effect on the process temperature, the uniformity, the size and shape of the crystallites of the solid SCS product [40].

Nevertheless, in apply of the efficiency of decomposition of hydrocarbons to hydrogen and nanofibrous carbon, the effect of the fuel type on the properties of catalysts obtained by SCS has not been in-depth researched. Only citric acid [42], [43] and glycine [34,44] were used as fuels. At the same time, despite the fact that use of hexamethylenetetramine (HMT) as a fuel in the course of SCS is more promising as HMT is cheap, harmless and is manufactured on a large scale [41], the authors are not aware of publications on preparation and study of the catalyst prepared by the SCS method using HMT as a fuel specifically for hydrocarbon decomposition processes.

This work studies the peculiarities of combustion of aqueous solutions containing HMT and $\mathrm{Ni}, \mathrm{Cu}$ and $\mathrm{Al}$ nitrates on the basis of thermochemical calculations, physical and chemical studies and tests of the obtained products as unreduced catalysts in the course of methane decomposition. The efficiency of the use of unreduced $\mathrm{NiO} / \mathrm{Al}_{2} \mathrm{O}_{3}$ catalyst, obtained in one stage by the SCS at a lack of HMT was confirmed experimentally.

\section{Research methodology}




\subsection{Thermochemical analysis of Hexamethylenetetramine - Nitrates Solution Combustion Synthesis of NiO-Ni-CuO-Cu- $\mathrm{Al}_{2} \mathrm{O}_{3}$ Catalyst}

The thermochemical calculations shown below, are based on the application of generalized chemical equations, derived with the certain assumptions regarding the specifics features of the SCS process. In all cases the $\mathrm{H}_{2} \mathrm{O}-\mathrm{C}_{6} \mathrm{H}_{12} \mathrm{~N}_{4}-\mathrm{Ni}\left(\mathrm{NO}_{3}\right)_{2}-\mathrm{Cu}\left(\mathrm{NO}_{3}\right)_{2}-\mathrm{Al}\left(\mathrm{NO}_{3}\right)_{3}$ solution was taken as an initial reaction mixture. The molar fuel/unreduced catalyst ratio, in the case when both nitrates and fuel are completely used up in the reaction of fuel oxidation with nitrates, will be called stoichiometric $\left(y_{s t}\right)$. In practice, the combustion of solutions can occur in the conditions of three types: stoichiometric fuel content, the excess and shortage of fuel with respect to the stoichiometric content. In this framework, the combustion process will be characterised by the fuel excess coefficient,

$$
\varphi=\frac{y}{y_{s t}},
$$

where $y$ - the real molar fuel/catalyst ratio. The fuel excess coefficient indicates the amount by which the content of fuel in the solution is larger $(\varphi>1)$ or smaller $(\varphi<1)$ compared to the stoichiometric $(\varphi=1)$.

\subsubsection{Derivation of the generalised equation for the complete oxidation of HMT by Ni, $\mathrm{Cu}$ and $\mathrm{Al}$ nitrates with present of molecular oxygen as reactant or product}

It has been shown [45] that the products obtained by the SCS under the $\varphi>1$ may contain oxides of easily reducible metals and metallic phases. Therefore it is assumed that the unreduced catalyst obtained by the combustion of solutions containing $\mathrm{Ni}, \mathrm{Cu}$ and $\mathrm{Al}$ nitrates will contain $\mathrm{Ni}$, $\mathrm{NiO}, \mathrm{Cu}, \mathrm{CuO}$ and $\mathrm{Al}_{2} \mathrm{O}_{3}$ (hardly reducible oxides). The chemical composition of this unreduced catalyst will be characterised by the mole fraction:

$x_{N i}=N_{N i} / N_{k}, x_{N i O}=N_{N i O} / N_{k}, x_{C u}=N_{C u} / N_{k}, x_{C u O}=N_{C u O} / N_{k}, x_{A l 203}=N_{A l 203} / N_{k}$,

where $N_{N i}, N_{N i O}, N_{C u}, N_{C u O}, N_{A l 203}$ - mole numbers of $\mathrm{Ni}, \mathrm{NiO}, \mathrm{Cu}, \mathrm{CuO}$ and $\mathrm{Al}_{2} \mathrm{O}_{3}$ in the catalyst; $N_{k}=\left(N_{N i}+N_{N i O}\right)+\left(N_{C u}+N_{C u O}\right)+N_{A l 203}=N_{k N i}+N_{k C u}+N_{A l 203}-$ total number of moles in the catalyst; $N_{k N i}=\left(N_{N i}+N_{N i O}\right), N_{k C u}=\left(N_{C u}+N_{C u O}\right)-$ total amounts of nickel and copper in the catalyst. It follows from Eqs. (2) that:

$$
x_{N i}+x_{N i O}+x_{C u}+x_{C u O}+x_{A l 203}=1 \text {. }
$$

Therefore, four independent parameters are needed to describe the composition of the catalyst. It is sometimes convenient to use a different set of four parameters:

$$
x_{A l 203}, a_{k}=x_{k C u} /\left(x_{k N i}+x_{k C u}\right), \varepsilon_{N i}=x_{N i} /\left(x_{N i}+x_{N i O}\right), \varepsilon_{C u}=x_{C u} /\left(x_{C u}+x_{C u O}\right)
$$

whence

$$
\begin{aligned}
& x_{k C u}=a_{k}\left(1-x_{A l 203}\right), \quad x_{k N i}=\left(1-a_{k}\right)\left(1-x_{A l 203}\right), \\
& x_{N i O}=\left(1-\varepsilon_{N i}\right)\left(1-a_{k}\right)\left(1-x_{A l 203}\right), x_{N i}=\varepsilon_{N i}\left(1-a_{k}\right)\left(1-x_{A l 203}\right), \\
& x_{C u O}=\left(1-\varepsilon_{C u}\right) a_{k}\left(1-x_{A l 203}\right), \quad x_{C u}=\varepsilon_{C u} a_{k}\left(1-x_{A l 203}\right)
\end{aligned}
$$


The generalised reaction equation of the solution combustion for the case of several nitrates and a fuel can be obtained by combining the equations for the decomposition of nitrates and oxidation of the fuel by oxygen, similar to [37,38], where the solution contained only one nitrate.

Let us write down equations for the reactions of nitrates decomposition with stoichiometric coefficients multiplied by the mole fraction of the corresponding component in the unreduced catalyst, which will be obtained as the result SCS:

- decomposition of nitrates to metal oxides, nitrogen and oxygen:

$$
\begin{aligned}
& x_{\mathrm{NiO}} \mathrm{Ni}\left(\mathrm{NO}_{3}\right)_{2}=x_{\mathrm{NiO}} \mathrm{NiO}+x_{\mathrm{NiO}} \mathrm{N}_{2}+x_{\mathrm{NiO}} 5 / 2 \mathrm{O}_{2} \text {, } \\
& x_{\mathrm{CuO}} \mathrm{Cu}\left(\mathrm{NO}_{3}\right)_{2}=x_{\mathrm{CuO}} \mathrm{CuO}+x_{\mathrm{CuO}} \mathrm{N}_{2}+x_{\mathrm{CuO}} 5 / 2 \mathrm{O}_{2} \text {, } \\
& x_{A l 203} 2 \mathrm{Al}\left(\mathrm{NO}_{3}\right)_{3}=x_{\mathrm{Al2O} 3} \mathrm{Al}_{2} \mathrm{O}_{3}+x_{\mathrm{Al2O} 3} 3 \mathrm{~N}_{2}+x_{\mathrm{Al2O} 3} 15 / 2 \mathrm{O}_{2} \text {; }
\end{aligned}
$$

- decomposition of nitrates to metals, nitrogen and oxygen:

$$
\begin{aligned}
& x_{\mathrm{Ni}} \mathrm{Ni}\left(\mathrm{NO}_{3}\right)_{2}=x_{\mathrm{Ni}} \mathrm{Ni}+x_{\mathrm{Ni}} \mathrm{N}_{2}+x_{\mathrm{Ni}} 3 \mathrm{O}_{2}, \\
& x_{\mathrm{Cu}} \mathrm{Cu}\left(\mathrm{NO}_{3}\right)_{2}=x_{\mathrm{Cu}} \mathrm{Cu}+x_{\mathrm{Cu}} \mathrm{N}_{2}+x_{\mathrm{Cu}} 3 \mathrm{O}_{2} ;
\end{aligned}
$$

- oxidation of HMT by oxygen:

$$
y \mathrm{C}_{6} \mathrm{H}_{12} \mathrm{~N}_{4}+9 y \mathrm{O}_{2}=6 y \mathrm{H}_{2} \mathrm{O}+6 y \mathrm{CO}_{2}+2 y \mathrm{~N}_{2} \text {, }
$$

where $y$ is the amount of fuel contained in the reaction mixture used to produce one mole of unreduced catalyst.

Next, by adding up the left and right parts of Eqs (r1-r6) and with account of the equation (3), it is possible to obtain a generalised equation for the SCS, normalized to one mole of unreduced catalyst:

$$
\begin{aligned}
& \left(x_{\mathrm{Ni}}+x_{\mathrm{NiO}}\right) \mathrm{Ni}\left(\mathrm{NO}_{3}\right)_{2}+\left(x_{\mathrm{Cu}}+x_{\mathrm{CuO}}\right) \mathrm{Cu}\left(\mathrm{NO}_{3}\right)_{2}+2 x_{\mathrm{Al} 203} \mathrm{Al}\left(\mathrm{NO}_{3}\right)_{3}+y \mathrm{C}_{6} \mathrm{H}_{12} \mathrm{~N}_{4}+ \\
& +\frac{1}{2}\left(18 y-5-x_{N i}-x_{C u}-10 x_{A l 203}\right) O_{2}=
\end{aligned}
$$

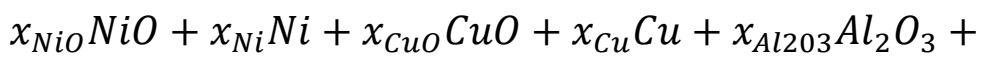

$$
\begin{aligned}
& +\left(1+2 x_{A l 203}+2 y\right) \mathrm{N}_{2}+6 y \mathrm{H}_{2} \mathrm{O}+6 y \mathrm{CO}_{2}
\end{aligned}
$$

Eq. (r7) does not account the effect of the transition of water present in the solution from liquid to gaseous state, which is crucial for the thermochemical analysis. To correct for this, it is necessary to introduce water as liquid and gas with the same stoichiometric coefficient $m$ into the left and right parts of Eq. (r7) respectively. The $m$ parameter is defined as the ratio of water mole number in the solution at the ignition moment to the number of moles of synthesised unreduced catalyst $\left(\mathrm{mol}_{\mathrm{H} 2 \mathrm{O}} / \mathrm{mol}_{\text {cat }}\right)$. In addition, it should be taken into the account that for the stoichiometric mixture the oxygen coefficient in the reaction Eq. (r7) should be equal to zero, i.e. $5+x_{N i}+x_{C u}+$ $10 x_{A l 203}-18 y_{s t}=0$, from which

$$
y_{s t}=\frac{5+x_{N i}+x_{C u}+10 x_{A l 203}}{18},
$$

and then from Eq. (1)

$$
y=\varphi y_{s t}=\frac{\varphi}{18}\left(5+x_{N i}+x_{C u}+10 x_{A l 203}\right)
$$


With account of water content and substitution of Eq. (7) into Eq. (r7) it is possible to derive a generalized reaction equation in terms of fuel excess coefficient $(\varphi)$ normalised to one mole of unreduced catalyst as follows:

$$
\begin{aligned}
& \left(x_{\mathrm{Ni}}+x_{\mathrm{NiO}}\right) \mathrm{Ni}\left(\mathrm{NO}_{3}\right)_{2}+\left(x_{\mathrm{Cu}}+x_{\mathrm{CuO}}\right) \mathrm{Cu}\left(\mathrm{NO}_{3}\right)_{2}+2 x_{\mathrm{Al203}} \mathrm{Al}\left(\mathrm{NO}_{3}\right)_{3}+ \\
& +\frac{\varphi}{18}\left(5+x_{\mathrm{Ni}}+x_{\mathrm{Cu}}+10 x_{\mathrm{Al203}}\right) \mathrm{C}_{6} \mathrm{H}_{12} \mathrm{~N}_{4}+\mathrm{mH}_{2} \mathrm{O}_{(\mathrm{l})}= \\
& x_{\mathrm{NiO}} \mathrm{NiO}+x_{\mathrm{Ni}} \mathrm{Ni}+x_{\mathrm{CuO}} \mathrm{CuO}+x_{\mathrm{Cu}} \mathrm{Cu}+x_{A l 203} \mathrm{Al}_{2} \mathrm{O}_{3}+\frac{\varphi}{3}\left(5+x_{N i}+x_{C u}+10 x_{A l 203}\right) \mathrm{CO}_{2}+ \\
& +\left(1+2 x_{A l 203}+\frac{\varphi}{9}\left(5+x_{N i}+x_{C u}+10 x_{A l 203}\right)\right) N_{2}+\frac{1-\varphi}{2}\left(5+x_{N i}+x_{C u}+10 x_{A l 203}\right) O_{2} \\
& \quad+\left(\frac{\varphi}{3}\left(5+x_{N i}+x_{C u}+10 x_{A l 203}\right)+m\right) H_{2} O_{(g)} .
\end{aligned}
$$

Eq. (r8) corresponds to the combustion process of the solution, which is characterised by the water content $\mathrm{m}$ and the fuel excess coefficient $\varphi<1$, at which the excess nitrates decompose with the release of oxygen.

When $\varphi>1$, the oxygen participates in the reaction as a reactant. Therefore, it must be moved into the left side of the Eq. (r8):

$$
\begin{aligned}
& \left(x_{\mathrm{Ni}}+x_{\mathrm{NiO}}\right) \mathrm{Ni}\left(\mathrm{NO}_{3}\right)_{2}+\left(x_{\mathrm{Cu}}+x_{\mathrm{CuO}}\right) \mathrm{Cu}\left(\mathrm{NO}_{3}\right)_{2}+2 x_{\mathrm{Al203}} \mathrm{Al}\left(\mathrm{NO}_{3}\right)_{3}+ \\
& +\frac{\varphi}{18}\left(5+x_{\mathrm{Ni}}+x_{\mathrm{Cu}}+10 x_{\mathrm{Al203}}\right) \mathrm{C}_{6} \mathrm{H}_{12} \mathrm{~N}_{4}+\mathrm{mH}_{2} \mathrm{O}_{(\mathrm{l})}+\frac{\varphi-1}{2}\left(5+x_{\mathrm{Ni}}+x_{\mathrm{Cu}}+10 x_{A l 203}\right) \mathrm{O}_{2}= \\
& x_{\mathrm{NiO}} \mathrm{NiO}+x_{\mathrm{Ni}} \mathrm{Ni}+x_{\mathrm{CuO}} \mathrm{CuO}+x_{\mathrm{Cu}} \mathrm{Cu}+x_{A l 203} \mathrm{Al}_{2} \mathrm{O}_{3}+\frac{\varphi}{3}\left(5+x_{N i}+x_{C u}+10 x_{A l 203}\right) \mathrm{CO}_{2}+ \\
& \left(1+2 x_{A l 203}+\frac{\varphi}{9}\left(5+x_{N i}+x_{C u}+10 x_{A l 203}\right)\right) N_{2}+ \\
& \left(\frac{\varphi}{3}\left(5+x_{N i}+x_{C u}+10 x_{A l 203}\right)+m\right) \mathrm{H}_{2} \mathrm{O} .
\end{aligned}
$$

Equation above corresponds to the condition when the excess fuel is oxidized by pure oxygen.

Reactions (r8) and (r8a) are normalised to one mole of catalyst. Therefore, their stoichiometric coefficients indicate how many moles of each reagent should be present in the solution to obtain 1 mole of unreduced catalyst at the set values of $x_{\mathrm{NiO}}, x_{\mathrm{Ni}}, x_{\mathrm{CuO}}, x_{\mathrm{Cu}}, x_{\mathrm{Al2O} 3}, \varphi$, and $\mathrm{m}$.

In the case of a stoichiometric mixture $(\varphi=1)$ Eqs. (r8) and (r8a) take the same form:

$$
\begin{aligned}
& \left(x_{\mathrm{Ni}}+x_{\mathrm{NiO}}\right) \mathrm{Ni}\left(\mathrm{NO}_{3}\right)_{2}+\left(x_{\mathrm{Cu}}+x_{\mathrm{CuO}}\right) \mathrm{Cu}\left(\mathrm{NO}_{3}\right)_{2}+2 x_{\mathrm{Al203}} \mathrm{Al}\left(\mathrm{NO}_{3}\right)_{3}+ \\
& +\frac{1}{18}\left(5+x_{\mathrm{Ni}}+x_{\mathrm{Cu}}+10 x_{\mathrm{Al203}}\right) \mathrm{C}_{6} \mathrm{H}_{12} \mathrm{~N}_{4}+\mathrm{mH}_{2} \mathrm{O}_{(\mathrm{l})}= \\
& x_{\mathrm{NiO}} \mathrm{NiO}+x_{\mathrm{Ni}} \mathrm{Ni}+x_{\mathrm{CuO}} \mathrm{CuO}+x_{\mathrm{Cu}} \mathrm{Cu}+x_{A l 203} \mathrm{Al}_{2} \mathrm{O}_{3}+\frac{1}{3}\left(5+x_{\mathrm{Ni}}+x_{\mathrm{Cu}}+10 x_{A l 203}\right) \mathrm{CO}_{2}+ \\
& \quad+\left(1+2 x_{A l 203}+\frac{1}{9}\left(5+x_{\mathrm{Ni}}+x_{\mathrm{Cu}}+10 x_{A l 203}\right)\right) \mathrm{N}_{2}+ \\
& \quad+\frac{1}{3}\left(5+x_{\mathrm{Ni}}+x_{\mathrm{Cu}}+10 x_{\mathrm{Al203}}+3 m\right) \mathrm{H}_{2} \mathrm{O}_{(\mathrm{g})} .
\end{aligned}
$$


2.1.2. Derivation of the generalised equation for $\mathrm{HMT}-\mathrm{Ni}\left(\mathrm{NO}_{3}\right)_{2}-\mathrm{Cu}\left(\mathrm{NO}_{3}\right)_{2}-$ $\mathrm{Al}\left(\mathrm{NO}_{3}\right)_{3}$ system at $\varphi>1$, where the excess fuel is oxidised by the molecular oxygen of air

With burning occurring in air the adiabatic combustion temperature will be lower, since the nitrogen in air will be heated alongside the reaction products. This effect can be accounted for by introduction of nitrogen with stoichiometric coefficients which are dependent on the air composition, into the left and right hand sides of the Eq. (r8a). In this case with the assumption that the molar ratio of oxygen/nitrogen $=21 / 79$, we can get the following generalised reaction equation:

$$
\begin{aligned}
& \left(x_{N i}+x_{N i O}\right) N i\left(N_{3}\right)_{2}+\left(x_{C u}+x_{C u O}\right) C u\left(N_{3}\right)_{2}+2 x_{A l 203} A l\left(N_{3}\right)_{3}+ \\
& +\frac{\varphi}{18}\left(5+x_{N i}+x_{C u}+10 x_{A l 203}\right) C_{6} H_{12} N_{4}+\frac{\varphi-1}{2}\left(5+x_{N i}+x_{C u}+10 x_{A l 203}\right) O_{2}+m H_{2} O_{(l)}+ \\
& +\frac{79}{21} \frac{(\varphi-1)}{2}\left(5+x_{N i}+x_{C u}+10 x_{A l 203}\right) N_{2(g)}= \\
& x_{N i O} N i O+x_{N i} N i+x_{C u O} \mathrm{CuO}+x_{C u} C u+x_{A l 203} A_{2} O_{3}+\frac{\varphi}{3}\left(5+x_{N i}+x_{C u}+10 x_{A l 203}\right) C O_{2}+ \\
& \quad+\left(1+2 x_{A l 203}+\left(\frac{\varphi}{9}+\frac{79}{21} \frac{(\varphi-1)}{2}\right)\left(5+x_{N i}+x_{C u}+10 x_{A l 203}\right)\right) N_{2(g)}+ \\
& \quad+\left(\frac{\varphi}{3}\left(5+x_{N i}+x_{C u}+10 x_{A l 203}\right)+m\right) H_{2} O_{(g)} .
\end{aligned}
$$

\subsubsection{Derivation of the generalised equation for $\mathrm{HMT}-\mathrm{Ni}\left(\mathrm{NO}_{3}\right)_{2}-\mathrm{Cu}\left(\mathrm{NO}_{3}\right)_{2}-$} $\mathrm{Al}\left(\mathrm{NO}_{3}\right)_{3}$ system, at $\varphi>1$, where the excess fuel decomposes to simpler substances

In this proposed version of SCS it is assumed, that for the $\varphi>1$ condition, $\frac{1}{18}\left(5+x_{N i}+x_{C u} 10 x_{A l 203}\right)$ moles of fuel per one mole of unreduced catalyst get consumed like in stoichiometric combustion according to the reaction represented by Eq. (r9).

The remaining part of HMT, $\left(\frac{1}{18}(\varphi-1)\left(5+x_{N i}+x_{C u} 10 x_{A l 203}\right)\right.$ moles of HMT per 1 mole of catalyst), decomposes to simpler substances in according to the following reaction of complete decomposition:

$$
\begin{gathered}
\frac{1}{18}(\varphi-1)\left(5+x_{N i}+x_{C u} 10 x_{A l 203}\right) C_{6} H_{12} N_{4}=\frac{1}{3}(\varphi-1)\left(5+x_{N i}+x_{C u} 10 x_{A l 203}\right) C+ \\
\frac{1}{3}(\varphi-1)\left(5+x_{N i}+x_{C u} 10 x_{A l 203}\right) H_{2}+\frac{1}{9}(\varphi-1)\left(5+x_{N i}+x_{C u} 10 x_{A l 203}\right) N_{2} .
\end{gathered}
$$

In this approximation the generalized equation for the SCS normalised to one mole of unreduced catalyst is achieved by adding the Eqs. (r9) and (r11):

$$
\begin{aligned}
& \left(x_{\mathrm{Ni}}+x_{\mathrm{NiO}}\right) \mathrm{Ni}\left(\mathrm{NO}_{3}\right)_{2}+\left(x_{\mathrm{Cu}}+x_{\mathrm{CuO}}\right) \mathrm{Cu}\left(\mathrm{NO}_{3}\right)_{2}+2 x_{\mathrm{Al203}} \mathrm{Al}\left(\mathrm{NO}_{3}\right)_{3}+ \\
& +\frac{\varphi}{18}\left(5+x_{\mathrm{Ni}}+x_{\mathrm{Cu}}+10 x_{\mathrm{Al203}}\right) \mathrm{C}_{6} \mathrm{H}_{12} \mathrm{~N}_{4}+\mathrm{mH}_{2} \mathrm{O}_{(\mathrm{l})}= \\
& x_{\mathrm{NiO}} \mathrm{NiO}+x_{\mathrm{Ni}} \mathrm{Ni}+x_{\mathrm{CuO}} \mathrm{CuO}+x_{\mathrm{Cu}} \mathrm{Cu}+x_{\mathrm{Al203}} \mathrm{Al}_{2} \mathrm{O}_{3}+\frac{1}{3}\left(5+x_{\mathrm{Ni}}+x_{\mathrm{Cu}}+10 x_{\mathrm{Al203}}\right) \mathrm{CO}_{2(\mathrm{~g})}+
\end{aligned}
$$




$$
\begin{aligned}
& +\left(1+2 x_{A l 203}+\frac{\varphi}{9}\left(5+x_{N i}+x_{C u}+10 x_{A l 203}\right)\right) N_{2(g)}+\frac{1}{3}(\varphi-1)\left(5+x_{N i}+x_{C u} 10 x_{A l 203}\right) C+ \\
& \frac{1}{3}(\varphi-1)\left(5+x_{N i}+x_{C u} 10 x_{A l 203}\right) H_{2(g)}+\left(\frac{1}{3}\left(5+x_{N i}+x_{C u}+10 x_{A l 203}\right)+m\right) H_{2} O_{(g)} . \quad(\mathrm{r} 12)
\end{aligned}
$$

\subsubsection{Derivation of the generalized equation for the combustion of the solution with the formation of nitrogen dioxide (low temperature case, $\varphi<1, x_{N i}=x_{C u}=0$ )}

When deriving the reaction Eq. (r8), it was assumed that in the case of a fuel shortage the excess nitrates would decompose to metal oxides, oxygen and nitrogen, as outlined in Eqs. (r1)-(r5). These reactions are possible at sufficiently high temperatures, when nitrogen oxides decompose sufficiently quickly.

At relatively low temperatures and $\varphi<1$ a more realistic conversion scheme may be based on the assumption that the $\varphi$ fraction of the total amount of nitrates participates in the combustion process without formation of the metallic phases $\left(x_{N i}=x_{C u}=0\right)$, via the reaction represented by Eq. (r9):

$$
\begin{gathered}
\varphi x_{\mathrm{NiO}} \mathrm{Ni}\left(\mathrm{NO}_{3}\right)_{2}+\varphi x_{\mathrm{CuO}} \mathrm{Cu}\left(\mathrm{NO}_{3}\right)_{2}+2 \varphi x_{A l 203} \mathrm{Al}\left(\mathrm{NO}_{3}\right)_{3}+\frac{5}{18} \varphi\left(1+2 x_{A l 203}\right) C_{6} \mathrm{H}_{12} \mathrm{~N}_{4}= \\
\varphi x_{\mathrm{NiO}} \mathrm{NiO}+\varphi x_{\mathrm{CuO}} \mathrm{CuO}+\varphi x_{A l 203} \mathrm{Al}_{2} \mathrm{O}_{3}+\frac{5}{3} \varphi\left(1+2 x_{A l 203}\right) \mathrm{CO}_{2}+ \\
+\varphi\left(1+2 x_{A l 203}+\frac{5}{9}\left(1+2 x_{A l 203}\right)\right) N_{2}+\frac{5}{3} \varphi\left(1+2 x_{A l 203}\right) H_{2} O_{(g)} .
\end{gathered}
$$

The remaining $(1-\varphi)$ fraction of the total amount of nitrate decomposes to metal oxides, nitrogen dioxide and hydrogen:

$$
\begin{aligned}
& (1-\varphi) x_{\mathrm{NiO}} \mathrm{Ni}\left(\mathrm{NO}_{3}\right)_{2}=(1-\varphi) x_{\mathrm{NiO}} \mathrm{NiO}+2(1-\varphi) x_{\mathrm{NiO}} \mathrm{NO}_{2(g)}+\frac{1}{2}(1-\varphi) x_{\mathrm{NiO}} \mathrm{O}_{2}(\mathrm{~g}) \\
& (1-\varphi) x_{\mathrm{CuO}} \mathrm{Cu}\left(\mathrm{NO}_{3}\right)_{2}=(1-\varphi) x_{\mathrm{CuO}} \mathrm{CuO}+2(1-\varphi) x_{\mathrm{CuO}} \mathrm{NO}_{2(g)}+\frac{1}{2}(1-\varphi) x_{\mathrm{CuO}} \mathrm{O}_{2(g)} \\
& 2(1-\varphi) x_{A l 203} A l\left(N O_{3}\right)_{3}=(1-\varphi) x_{A l 203} A l_{2} O_{3}+6(1-\varphi) x_{A l 203} N_{2}(g)+\frac{3}{2}(1-\varphi) x_{A l 203} O_{2(g)}
\end{aligned}
$$

The generalized reaction equation for the SCS within the framework of the considered assumptions is obtained by summing up Eqs. (r13) - (r16), taking into account the presence of water in the reaction mixture and the $x_{\mathrm{NiO}}+x_{\mathrm{CuO}}+x_{\mathrm{Al2O} 3}=1$ equality:

$$
\begin{aligned}
& x_{\mathrm{NiO}} \mathrm{Ni}\left(\mathrm{NO}_{3}\right)_{2}+x_{\mathrm{CuO}} \mathrm{Cu}\left(\mathrm{NO}_{3}\right)_{2}+2 x_{\mathrm{Al203}} \mathrm{Al}\left(\mathrm{NO}_{3}\right)_{3}+ \\
& +\frac{5 \varphi}{18}\left(1+2 x_{A l 203}\right) C_{6} H_{12} N_{4}+m H_{2} O_{(l)}= \\
& x_{\mathrm{NiO}} \mathrm{NiO}+x_{\mathrm{CuO}} \mathrm{CuO}+x_{\mathrm{Al203} \mathrm{Al}_{2} \mathrm{O}_{3}+\frac{5 \varphi}{3}\left(1+2 x_{\mathrm{Al203}}\right) \mathrm{CO}_{2}(\mathrm{~g})}+ \\
& +2(1-\varphi)\left(1+2 x_{A l 203}\right) N O_{2(g)}+\varphi\left(1+\frac{5}{9}\right)\left(1+2 x_{A l 203}\right) N_{2(g)}+ \\
& +\frac{1}{2}(1-\varphi)\left(1+2 x_{A l 203}\right) O_{2(g)}+\left(m+\frac{5 \varphi}{3}\left(1+2 x_{A l 203}\right)\right) H_{2} O_{(g)} \text {. }
\end{aligned}
$$

The generalized equations outlined above can be used to describe the SCS in systems containing one, two or three nitrate species. 


\subsubsection{Methodology for the calculation of the adiabatic combustion temperature $\left(T_{a d}\right)$ and amount of gaseous reaction products obtained per one mole of catalyst $\left(n_{g}\right)$}

The various equilibrium states of the described chemically reacting thermodynamic system at constant pressure is presented in Fig. 1. During the reaction the system moves adiabatically from state 1 to state 4 . Before the reaction, the system is characterised by enthalpy $H=H_{1}$ and temperature $T=T_{1} K$ (temperature of the reaction medium on the ignition moment). When the reaction is complete, the system is characterized by a different composition, enthalpy $H=H_{4}$ and tempetarure $T=T_{a d} K$.

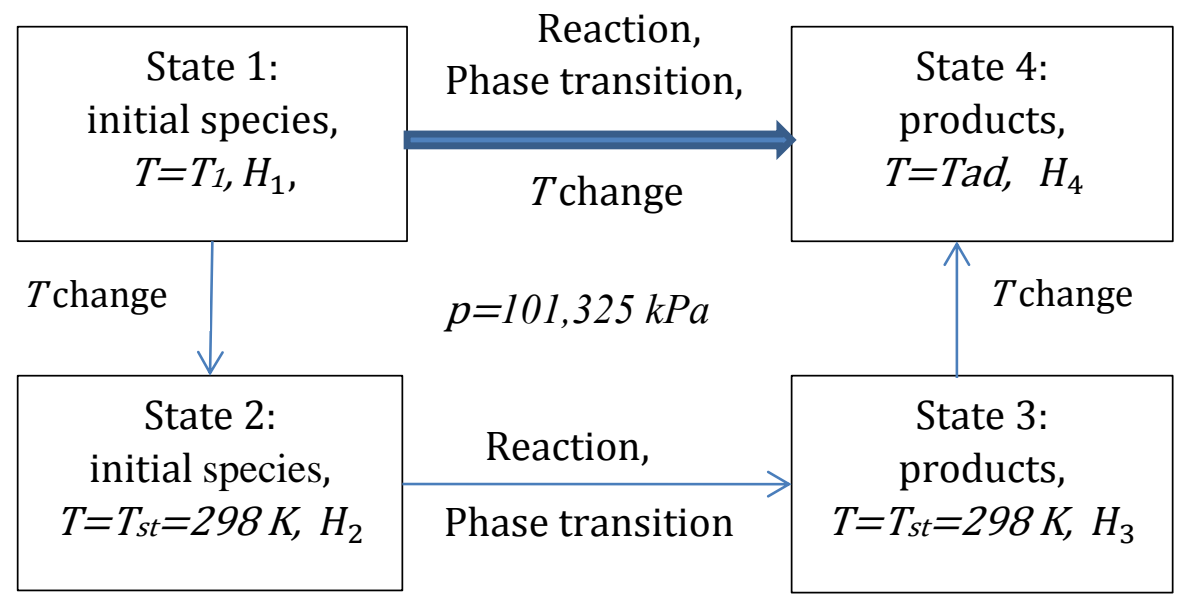

Fig. 1 - The progress scheme of the thermodynamic states

Due to enthalpy being a state function the enthalpy change is not process dependent quantity. Therefore the calculation of the direct adiabatic transition from state 1 to 4 can be substituted by a sequence of state transitions from $1 \rightarrow 2 \rightarrow 3 \rightarrow 4$, as it shown in Fig. 1. At the same time, given that the enthalpy does not change during the adiabatic process at constant pressure, we can write:

$$
\begin{aligned}
& \Delta H_{1-4}=H_{4}-H_{1}=\left(H_{4}-H_{3}\right)+\left(H_{3}-H_{2}\right)+\left(H_{2}-H_{1}\right)= \\
& \qquad \Delta H_{1-2}+\Delta H_{2-3}+\Delta H_{3-4}=0 \text {, where } \\
& \Delta H_{1-2}=\int_{T=T_{1}}^{T=298} \sum_{i=1}^{k}\left|v_{i}\right| c_{p i} d T
\end{aligned}
$$

- the change of the enthalpy of the initial mixture when its temperature changes from $T=T_{1}$ to standard temperature $T=T_{s t}=298 \mathrm{~K}$;

$\Delta H_{2-3}=\sum_{j=1}^{l} v_{j} H_{j}^{0}-\sum_{i=1}^{k}\left|v_{i}\right| H_{i}^{0}$

- the difference between the total enthalpy of formation of the final and initial reaction mixture;

$\Delta H_{3-4}=\int_{T=298}^{T=T_{a d}} \sum_{j=1}^{l} v_{j} c_{p j} d T$

- the change of the enthalpy of reaction products when their temperature changes from $T_{s t}=$ $298 \mathrm{~K}$ to $T=T_{a d}$. 
In the Eqs. (9)-(11) $c_{p i}, c_{p j}-$ molar specific heat capacities of the initial $(i)$ and final $(j)$ species, (including the species that are chemically inert); $v_{i}, v_{j}$ - stoichiometric coefficients related to initial and final species, respectively, in the respective generalized reaction equation; $k, l-$ the number of species present in the initial and final compositions, respectively; $H_{i}^{0}$, $H_{j}^{0}$ - the enthalpies of formation of the initial and final substances under normal conditions, respectively.

Substituting Eqs. (9)-(11) into Eq. (8) resulted in an expression from which the adiabatic temperature $\left(T_{a d}\right)$ can be determined if the properties of the species and the stoichiometric coefficients of the generalized reaction equation are known:

$\int_{T=T_{1}}^{T=298} \sum_{i=1}^{k}\left|v_{i}\right| c_{p i} d T+\sum_{j=1}^{l} v_{j} H_{j}^{0}-\sum_{i=1}^{k}\left|v_{i}\right| H_{i}^{0}+\int_{T=298}^{T=T_{a d}} \sum_{j=1}^{l} v_{j} c_{p j} d T=0$,

The dependence of the specific heat capacity on temperature is typically represented by a following relation:

$$
c_{p i}=a_{i}+b_{i} T+c_{i} T^{-2}
$$

In this case:

$$
\int c_{p i} d T=\int\left(a_{i}+b_{i} T+c_{i} T^{-2}\right) d T=a_{i} T+\frac{1}{2} b_{i} T^{2}-c_{i} T^{-1}
$$

By using Eq. (14), the integral Eq. (12) could be transformed into the following algebraic expression:

$$
\begin{gathered}
\left(298-T_{1}\right) \sum_{i=1}^{k}\left|v_{i}\right| a_{i}+\left(298^{2}-T_{1}^{2}\right) \sum_{i=1}^{k}\left|v_{i}\right| b_{i}-\left(\frac{1}{298}-\frac{1}{T_{1}}\right) \sum_{i=1}^{k}\left|v_{i}\right| c_{i}+\left(298-T_{1}\right)+ \\
\sum_{j=1}^{l} v_{j} H_{j}^{0}-\sum_{i=1}^{k}\left|v_{i}\right| H_{i}^{0}+\left(T_{a d}-298\right) \sum_{j=1}^{l} v_{j} a_{j}+ \\
\left(T_{a d}^{2}-298^{2}\right) \sum_{j=1}^{l} v_{j} b_{j}-\left(\frac{1}{T_{a d}}-\frac{1}{298}\right) \sum_{i=1}^{k} v_{j} c_{j}=0
\end{gathered}
$$

\begin{tabular}{|c|c|c|c|c|c|}
\hline \multirow[t]{2}{*}{ Properties $\rightarrow$} & $H^{0}$ & \multicolumn{3}{|c|}{$c_{p}=a+b T-c / T^{-2}$} & \multirow{3}{*}{ 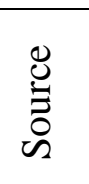 } \\
\hline & $\mathrm{kJ} / \mathrm{mol}$ & \multicolumn{3}{|c|}{$J /(\mathrm{mol} \cdot \mathrm{K})$} & \\
\hline Species $\downarrow$ & & $a$ & $b \cdot 10^{3}$ & $c \cdot 10^{-5}$ & \\
\hline $\mathrm{Al}\left(\mathrm{NO}_{3}\right)_{3(\mathrm{~s})}$ & -927 & $115^{*}$ & & & [46] \\
\hline $\mathrm{Al}_{2} \mathrm{O}_{3(\mathrm{~s})}$ & -1668 & 109,9 & 17,7 & 30,94 & [47] \\
\hline $\mathrm{Cu}(\mathrm{s})$ & 0 & 24,54 & 4,175 & 1,208 & [47] \\
\hline $\mathrm{Cu}\left(\mathrm{NO}_{3}\right)_{2(\mathrm{~s})}$ & $-303,1$ & $85^{*}$ & & & [46] \\
\hline
\end{tabular}

Table 1 shows the properties of the species used in the calculations.

Table 1. Standard enthalpy and specific heat capacity of species 


\begin{tabular}{|l|c|c|c|c|c|}
\hline $\mathrm{CuO}_{(\mathrm{s})}$ & $-154,9$ & 45,12 & 13,83 & 5,41 & {$[47]$} \\
\hline $\mathrm{Ni}(\mathrm{s})$ & 0 & 29,19 & 3,69 & & {$[47]$} \\
\hline $\mathrm{Ni}\left(\mathrm{NO}_{3}\right) 2(\mathrm{~s})$ & $-401,5$ & 28,13 & 190 & & {$[48]$} \\
\hline $\mathrm{NiO}_{(\mathrm{s})}$ & $-244,1$ & 44,3 & & & {$[47]$} \\
\hline $\mathrm{C}_{(\mathrm{gr})}$ & 0 & 11,19 & 10,9 & 4,885 & {$[47]$} \\
\hline $\mathrm{CO}_{2(\mathrm{~g})}$ & $-393,1$ & 43,21 & 11,04 & 8,166 & {$[47]$} \\
\hline $\mathrm{H}_{2(\mathrm{~g})}$ & 0 & 27,81 & 2,882 & & {$[47]$} \\
\hline $\mathrm{H}_{2} \mathrm{O}_{(\mathrm{g})}$ & $-241,9$ & 30,12 & 11,29 & & {$[47]$} \\
\hline $\mathrm{H}_{2} \mathrm{O}_{(\mathrm{l})}$ & $-285,6$ & 76,05 & & & {$[47]$} \\
\hline $\mathrm{N}_{2(\mathrm{~g})}$ & 0 & 27,87 & 4,192 & & {$[47]$} \\
\hline $\mathrm{NO}_{2(\mathrm{~g})}$ & 33.87 & 45,13 & 11,5 & 9,442 & {$[47]$} \\
\hline $\mathrm{O}_{2(\mathrm{~g})}$ & 0 & 31,43 & 3,39 & 3,768 & {$[47]$} \\
\hline $\mathrm{C}_{6} \mathrm{H}_{12} \mathrm{~N}_{4(\mathrm{~s})}$ & 124 & 152,3 & & & {$[49]$} \\
\hline$*$ indicative values & & & & \\
\hline
\end{tabular}

In this work, Eq. (15) was used to calculate $T_{a d}$, depending on:

- the used generalized reaction equation;

- the composition of the synthesised catalyst;

- the fuel excess coefficient;

- the water content in the initial mixture and the value of the temperature $\left(T_{1}\right)$ at the time of the ignition.

The total amount of gaseous reaction products obtained per one mole of catalyst $\left(n_{g}, \mathrm{~mol} / \mathrm{mol}_{\text {cat }}\right)$ was calculated as a quantity equal to the sum of the stoichiometric coefficients at the gaseous products in the corresponding generalized reaction equation.

\subsection{Experimental methodology}

\section{Catalyst preparation}

In this work, unreduced catalyst is considered to be a metallic catalyst precursor, consisting mainly of metal oxides. Typically, unreduced catalysts are reduced in a hydrogen stream before their use in the hydrocarbon decomposition processes [28].

As it follows from the reaction equations (r8), (r8a), (r10), (r12) and (r17) introduced above, to achieve 1 mole of unreduced catalyst, characterised by the $x_{\mathrm{NiO}} / x_{\mathrm{CuO}} / x_{\mathrm{Al2O}}$ fractions, the initial solution needs to contain $x_{N i O}$ moles of Ni nitrate, $x_{C u O}$ moles of $C u$ nitrate, $2 x_{A l 2 O 3}$ moles of $A l$ nitrate and $\frac{5 \varphi}{18}\left(1+2 x_{A l 203}\right)$ moles of HTM. When obtaining other amounts of catalyst of the same composition at the same $\varphi$, the HMT and nitrates contents in the initial solution were varied correspondingly.

The appropriate portions of nitrate hydrates were mixed up and heated. During the heating, the chemically bonded water was gradually released, resulting in nitrates being dissolved in their own crystalline water. Fifteen minutes after reaching $T=400 \mathrm{~K}$ the HMT mass, corresponding to $\varphi=0.7$, was added into the formed nitrate solution. Then the solution was cooled to room temperature while being stirred. At this stage the reaction mixture resembled a paste-like 
substance. The crucible with the cooled solution was placed into a muffle furnace, which was heated from room temperature $(298 \mathrm{~K})$ to the temperature $T_{o f f}=723 \mathrm{~K}$ at a rate of $V=1,10$ and $15 \mathrm{~K} / \mathrm{min}$. During heating, the reaction mixture spontaneously ignited, resulting in a sudden temperature rise of the reaction mixture, followed by its sharp decline. The local temperature of the reaction mixture during its heating and burning was recorded at a frequency of $1 \mathrm{~Hz}$.

The solid product of SCS was collected, crushed and sieved. The particles of $0.3-0.7 \mathrm{~mm}$ were further used as the unreduced catalyst for testing in the reaction of methane decomposition.

\section{Methane decomposition experiments}

The unreduced catalyst $(12 \mathrm{mg})$ was placed into a quartz vertical tubular up-flow reactor with an inlet argon flow rate at $1.2 \mathrm{~L} / \mathrm{h}$. The reactor was heated up in an electric resistance furnace and thermostabilised at $\mathrm{T}=823 \mathrm{~K}$. At this moment argon was replaced by methane ( $99.99 \%$ purity). The methane decomposition experiments were carried out at atmospheric pressure with methane inlet specific flow rate (MISFR) of $100 \mathrm{~L} /\left(\mathrm{h} \cdot g_{\text {cat }}\right)$. The concentration of the gaseous products was measured by gas chromatograph Chromos GC-1000. The specific yields of hydrogen and carbon were calculated from the carbon weight obtained during the deactivation period of the unreduced catalyst.

\section{Characterisation of the catalysts and carbon nanomaterials}

The phase composition of the samples was studied using powder X-ray diffraction analysis (XRD). XRD patterns were recorded on DRON-3 diffractometer using $\mathrm{Cu} \mathrm{K \alpha}$-emission line $(\lambda=0.15406 \mathrm{~nm})$. The average crystallite size was determined by using the Scherrer formula.

The surface structure and the elemental composition of the obtained unreduced catalysts and carbon nanofibers were studied by scanning electron microscopy (SEM) using S-3400n Hitachi with an energy dispersive X-ray spectroscopy (EDX) attachment from Oxford Instruments. The micrographs of the samples' surfaces were taken in the low vacuum regime by detecting the backscattered electrons.

The structure, size of the nanoparticles and the morphology of the synthesised catalyst and carbon nanofibers samples were studied by using Transmission electron microscopy (TEM), by JEOL JEM-2200 FS-CS.

\section{Results and Discussion \\ 3.1. Thermodynamic calculations}

As a result of thermochemical calculations with use of equations (r8), (r8a), (r10), (r12) and (r17) related to different conditions of the SCS process we have obtained data on the dependence of the adiabatic combustion temperature $\left(T_{a d}\right)$ as well as the amount of gaseous products $\left(n_{g}\right)$ on the generalized chemical equation used (peculiarities of the course of the process), ignition temperature $\left(T_{1}\right)$, water content $(m)$ in the reaction mixture at the time of ignition, fuel excess coefficient $(\varphi)$, and the composition of the obtained solid product (unreduced catalyst). The calculations showed that the ratio $x_{k N i}: x_{k C u}$ has a small influence on $T_{a d}$, which is explained by small differences between $\mathrm{Ni}$ and $\mathrm{Cu}$ nitrates decomposition enthalpies and between the amounts 
of $\mathrm{NiO}$ and $\mathrm{CuO}$ molar heat capacities. Therefore, for simplification, our calculation results are illustrated by the data obtained in an assumption that $x_{k C u}=0$. Obtained data showed that when $T_{1}$ rises, the condition $\Delta T_{a d}<\Delta T_{1}$ is fulfilled. For instance, in the surrounding area $T_{1}=423 \mathrm{~K}$ $\Delta T_{a d}\left(\Delta T_{1}\right) \approx(0.6 \div 0.65) \Delta T_{1}$.

Fig. 2 shows the calculation results for the adiabatic combustion temperature $\left(T_{a d}, K\right)$ of the HMT-Ni( $\left(\mathrm{NO}_{3}\right)_{2}-\mathrm{Al}\left(\mathrm{NO}_{3}\right)_{3}-\mathrm{H}_{2} \mathrm{O}$-solution and the quantity of formed gaseous products $\left(n_{g}, \mathrm{~mol} /\right.$ $\operatorname{mol}_{\text {cat }}$ ), depending on the fuel excess coefficient $\varphi$ and the solution water content $\left(\mathrm{m}, \mathrm{mol} / \mathrm{mol}_{\mathrm{cat}}\right)$ at the moment of ignition. The left and right vertical axes show the values of $T_{a d}$ and $n_{g}$, respectively. All data corresponds to the ignition temperature of the reaction mixture of $T_{1}=423 \mathrm{~K}$.

It can be seen that $T_{a d}$ strongly depends on the fuel excess coefficient $\varphi$ and the specific water content $m$ in the initial mixture at the moment of ignition. In the $\varphi \leq 1$ region, the process described by the reaction Eqs. (r8) or (r17) which correspond to the cases where excess nitrates decompose to molecular nitrogen and oxygen or to nitrogen dioxide and oxygen respectively (see above). It can be seen that $T_{a d}$ in the case of Eq. (r8) is higher than in case of (r17), which can be explained by the positive enthalpy of formation of nitrogen oxides.

At $\varphi \geq 1$, Eq. (r8a) corresponds to the condition where the excess fuel is oxidised by pure oxygen, allowing to achieve the highest values of $T_{a d}$. The limiting combustion temperature at these conditions is the adiabatic temperature of combustion of a stoichiometric mixture of pure HMT and pure oxygen.

Equation (r10) corresponds to the case of oxidation of excess fuel by molecular oxygen of air. The dependence of $T_{a d}(\varphi)$ in the $\varphi \geq 1$ region for $m=1.5$ decreases whereas for $m=6$ it increases. This tendency occurs regardless of $m$ as with the increasing $\varphi$ the limiting value of $T_{a d}(\varphi)$ should tend to the adiabatic temperature of combustion of a stoichiometric mixture of pure HMT and air. 


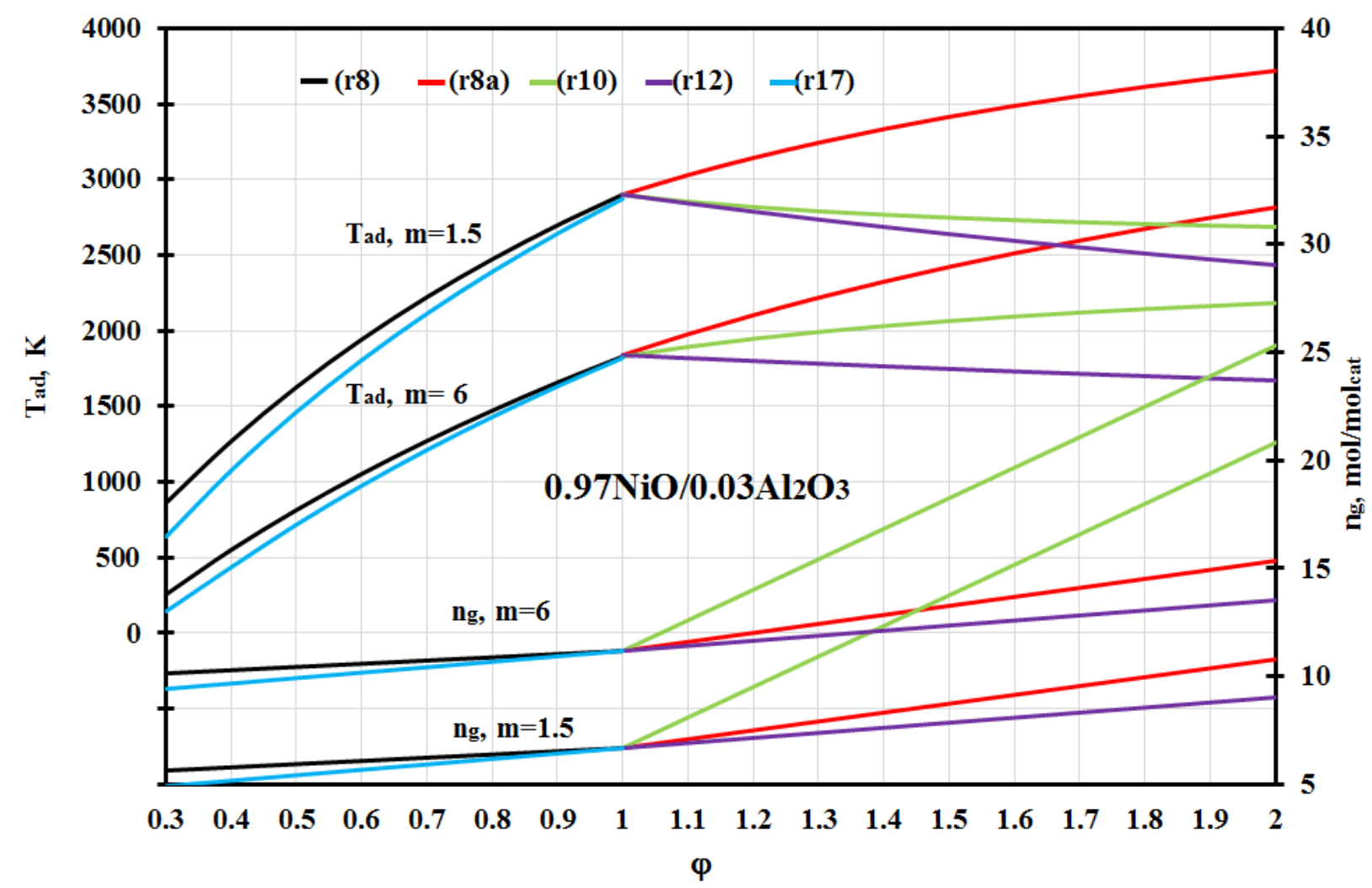

Fig. 2 - Dependence of the adiabatic combustion temperature $\left(T_{a d}, K\right)$ and gas amount $\left(n_{g}\right.$, $\left.\mathrm{mol} / \mathrm{mol}_{\text {cat }}\right)$ on the fuel excess coefficient $(\varphi)$ and the amount of water in the initial solution $(\mathrm{m}$, $m o l / \mathrm{mol}_{\text {cat }}$ ) for SCS of the $0.97 \mathrm{NiO} / 0.03 \mathrm{Al}_{2} \mathrm{O}_{3}$ catalyst.

Therefore, the highest $T_{a d}$ could be reached in the conditions of feeding molecular oxygen into the reaction zone at small $m$ and $\varphi \geq 1$. Due to the large values of $T_{a d}$, reactions (r8a) and (r10) are only of interest in specific cases, such as when using sufficiently dilute solutions (large $m$ ) or in laboratory conditions, characterised by the high thermal losses.

Significantly lower temperatures develop at $\varphi \geq 1$ if molecular oxygen is not supplied to the reaction zone. The reaction equation (r12) corresponds to these conditions and the assumption that excess fuel is decomposed into simple substances. As Fig. 2 shows, the $T_{a d}(\varphi)$ maximum is reached at $\varphi=1$ and, depending on $m$, can have values between 2000-3000 K. So the decrease in $T_{a d}$ with increasing $\varphi$ can be linked to the positive standard enthalpy of formation of hexamethylenetetramine. The conditions corresponding to Eq. (r12) may be of considerable interest from the point of view of obtaining the active metallic phase in a one stage by SCS at $\varphi>$ 1 [45].

In the $\varphi<1$ region the processes characterised by Eqs. (r8) and (r17) can proceed in parallel with a certain intensity depending on a temperature ranging from the ignition temperature $T_{1}$ and up to several thousands of $\mathrm{K}$ as function of the $\varphi$ and $m$ values. The calculations show that based on the conditions for sustainable combustion the $\varphi$ value must be more than 0.3 . Thus, a threshold increases with the increase in $m$, since for small $\varphi$ and large $m$, the condition $T_{a d}<T_{1}$ can be realized. 


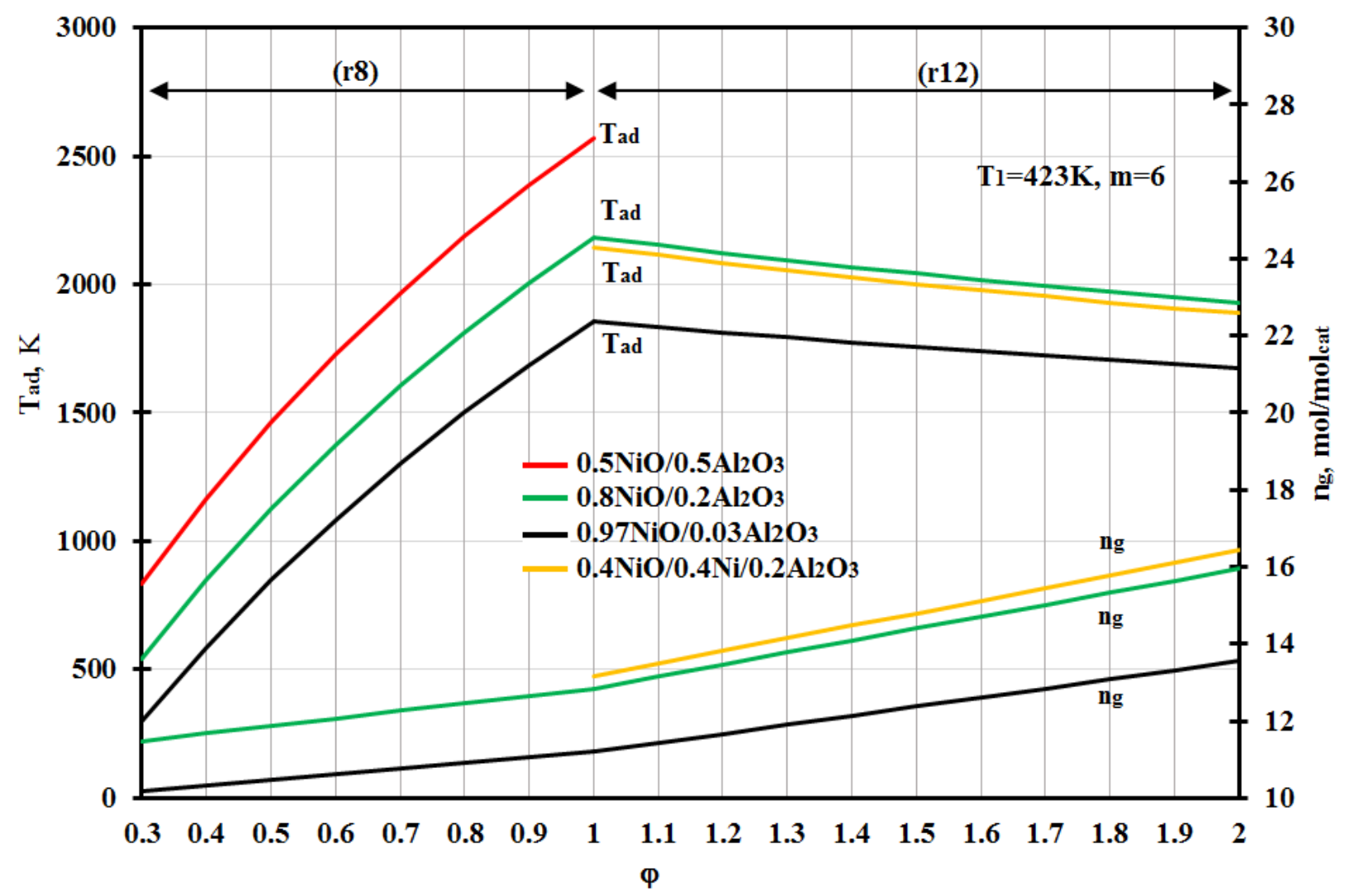

Fig. 3 - Dependence of the adiabatic combustion temperature $\left(T_{a d}, K\right)$ and gas amount $\left(n_{g}\right.$, $\mathrm{mol} / \mathrm{mol}_{\text {cat }}$ ) on the fuel excess coefficient $(\varphi)$ for various chemical compositions of unreduced catalyst obtained.

Fig. 3 shows the results for the combustion process proceeding via Eq.(r8) in the $\varphi \leq 1$ region and Eq. (r12) in the $\varphi \geq 1$ region. The graphs demonstrate the $T_{a d}(\varphi)$ dependencies on composition of the resulting unreduced catalyst. The numbers before the chemical formulas indicate the mole fraction of the corresponding oxide or metal phase present in the unreduced catalyst. It can be seen that $T_{a d}$ increases considerably (by hundreds of degrees) with an increase in the share of alumina in the catalyst. That can be explained by the fact that increase in the share of alumina in the catalyst requires double increase of the share of aluminum nitrate in the solution, that has a higher decomposition enthalpy than nickel nitrate or copper nitrate.

It has been noted that nickel and copper can be reduced to the metal phase under the excess fuel condition. However, as can be seen in Fig. 3, even in the case of reduction of $50 \%$ of nickel the value of $T_{a d}$ does not significantly diminish (by less than $40 \mathrm{~K}$ ).

It was shown in [36] that gaseous products, formed in large quantities during the SCS, have an effect on the structure and texture of the produced oxides, inhibit the growth of the particles and promote the production of a more dispersed solid product. Figs. 2 and 3 show the calculated $n_{g}(\varphi)$ dependences ( $m o l / m o l ~ c a t$, the $m$ is included in $n_{g}$ additively) when HMT is used as a fuel. It is observed that the $n_{g}(\varphi)$ dependence is increasing, regardless of the type of generalized chemical reaction equation (Fig. 2) and the composition of the synthesized catalyst (Fig. 3). The value of $n_{g}$ is greater when the content of the alumina and metal phase in the catalyst is higher, which is associated with additional release of nitrogen and oxygen.

\subsection{Experimental results}




\section{Catalyst synthesis}

Fig. 4 shows the dependencies of the reaction mixture (solid lines) and the muffle furnace's (dashed lines) temperatures on the reaction time of unreduced $\mathrm{NiO} / \mathrm{Al}_{2} \mathrm{O}_{3}$ catalysts synthesis by volumetric combustion of $\mathrm{H}_{2} \mathrm{O}-\mathrm{Ni}\left(\mathrm{NO}_{3}\right)_{2}-\mathrm{Al}\left(\mathrm{NO}_{3}\right)_{3}-\mathrm{HMT}$ solution at $\varphi=0.7$ and different heating rates of the muffle furnace $(V)$. The $0.97 \mathrm{NiO} / 0.03 \mathrm{Al}_{2} \mathrm{O}_{3}$ catalyst samples were obtained at $V=1,10$ and $15 \mathrm{~K} / \mathrm{min}$, hereinafter referred to as sample 1, sample 2, sample 3, respectively.

It can be seen that from the beginning of preheating to the ignition temperature $T_{1}$ the temperature of the solution follows the temperature of the muffle furnace, remaining at a lower level. The discrepancy between the temperature values increases with the increasing heating rate of the furnace. As the solution temperature reaches $T_{1}$, the ignition occurs and the temperature of the reaction mixture rapidly increases, reaching the $T_{\max }$ in minutes, after which it quickly falls to the furnace temperature. Furthermore, the temperature of the products continues to increase as the temperature of the furnace increases. After the furnace temperature reaches $T_{\text {off }}=723 \mathrm{~K}$ the heating turns off, which leads to the slow decrease of the products temperature.

It can be seen that in all cases the higher is the furnace heating rate, the higher is $T_{\max }$. It can be explained by the fact that at higher heating rates average temperature difference between the reaction volume and the surrounding environment (the furnace) decreases during the reaction period and, as a result, heat losses into the environment also decrease. Since the reaction time in the examined conditions is significantly smaller than the time of the furnace heating, it can be expected that the ignition temperature of the solution $\left(T_{1}\right)$ should not depend on the heating rate of the furnace. From fig. 4 it follows that for heating rates of $1 \mathrm{~K} / \mathrm{min}$ and $10 \mathrm{~K} / \mathrm{min}$ the ignition temperatures practically coincide, and insignificant decrease in $T_{1}$ at $V=15 \mathrm{~K} / \mathrm{min}$ can be connected with possible nonuniformity of heating of the reaction volume at high heating rates. It should be noted that in the present work the ignition temperature of $\mathrm{Ni}\left(\mathrm{NO}_{3}\right)_{2} / 0,062 \mathrm{Al}\left(\mathrm{NO}_{3}\right)_{3}$ HMT solution $T_{1}=433 \mathrm{~K}(\varphi=0.7)$ was lower than in [41], where $T_{1}=473 \mathrm{~K}$ (nickel nitrate HMT, $\varphi=1$ ), but higher than in [45], where $T_{1}=393 \mathrm{~K}$ (nickel nitrate $-\mathrm{HMT}, \varphi=2$ ). 


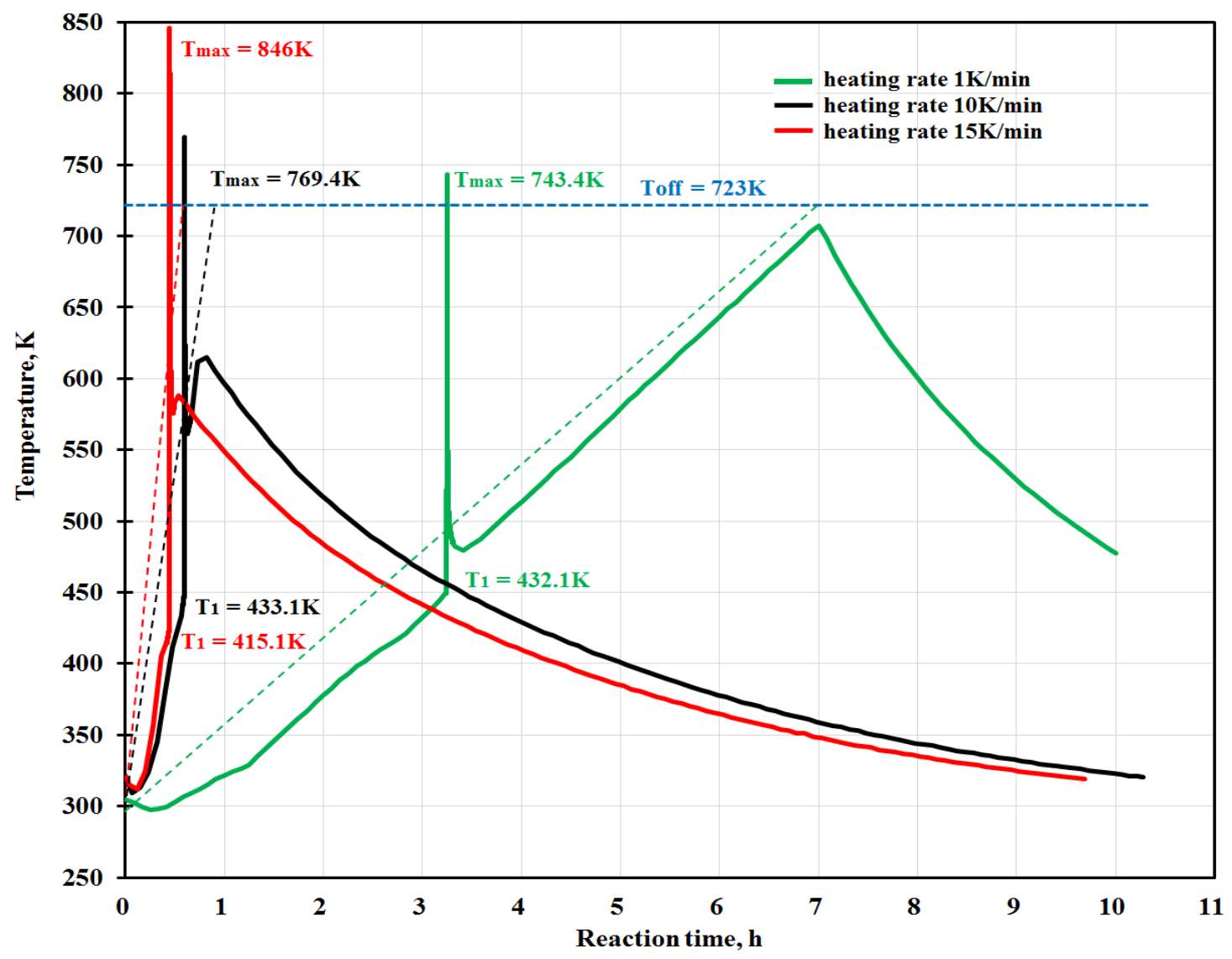

Fig. 4 - Experimental dependencies of the furnace (dashed lines) and reaction mixture temperature (solid lines) during the synthesis of $0.97 \mathrm{NiO} / 0.03 \mathrm{Al}_{2} \mathrm{O}_{3}$ catalyst via SCS process $(\varphi=0,7)$.

It can be assumed that in the observed SCS process a significant part of moisture is removed from the sample prior to the start of the reaction and at the moment of ignition $m<$ $6 \mathrm{~mol}_{\mathrm{H} 2 \mathrm{O}} / \mathrm{mol}_{\text {cat }}$ ( $\mathrm{m}=6$ corresponds to the maximum water content in the nickel nitrate hydrate). A comparison of the experimental (Fig. 4) and calculated (Fig. 2) data for $\varphi=0.7$ shows that $T_{\max } \ll T_{a d}$ for both $m=6$ and $m=1.5$. This indicates that uncontrolled enthalpy losses to the environment during the experiments make up a significant part of the reaction enthalpy that must be considered when scaling the SCS process.

Fig. 5 shows a typical morphology of the unreduced catalyst samples obtained in this work. It can be seen that when using the HMT, the solid product has a characteristic foam-like structure similar to that obtained in [45].
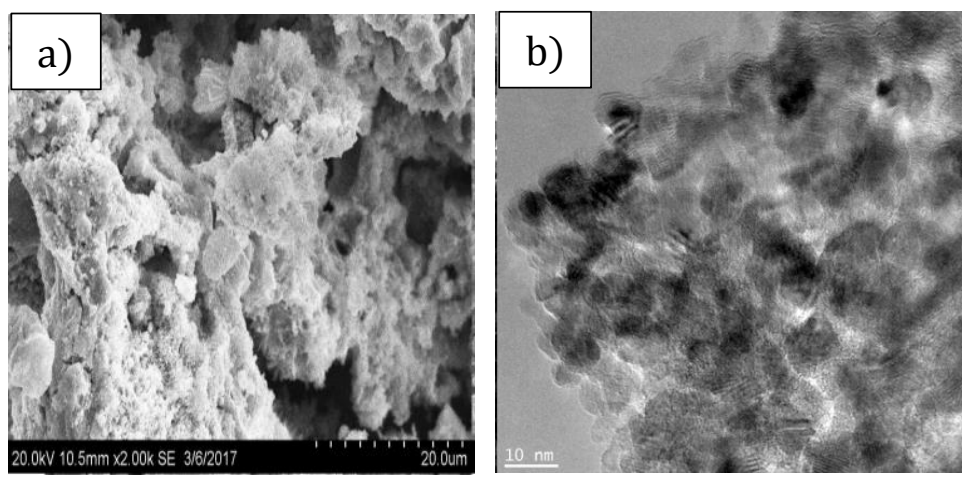
Fig. 5 - Images of the catalyst sample 3 obtained with SEM (a) and TEM (b).

Fig. 6 shows the XRD patterns of the SCS products in HMT-nickel nitrate system (catalyst samples 1 to 3). We can see that, in addition to nickel oxide a small amount of metallic nickel is present in the unreduced catalyst samples acquired at the muffle heating rates of 10 and $15 \mathrm{~K} / \mathrm{min}$. As the heating rate is reduced the magnitude of the peaks, corresponding to the metallic nickel, decreases.

Detection of metal nickel in the unreduced catalyst produced via SCS at $\varphi<1$, is unexpected as emergence of metal nickel at the conditions of a fuel shortage contradicts the equilibrium thermodynamics [50]. Formation of metal nanoparticles together with nickel oxide nanoparticles during SCS was observed experimentally only at $\varphi>1$ [37], [45], [50]. The mechanism of metal phase formation during SCS at the conditions of fuel excess $(\varphi>1$, glycine) was studied in work [50]. It was shown that reduction of nickel particles occurs due to excess of ammonia formed at the conditions of fuel excess on the intermediate stages of glycine decomposition. In [51] it was found that $\mathrm{NH}_{3}$ is also formed during HMT decomposition. Therefore, it can be assumed that general mechanisms of metal phase reduction in the course of SCS using glycine and HMT at the conditions of excess fuel are similar. At the same time the emergence of metal phase in SCS products at $\varphi<1$ can be explained by non-equilibrium conditions of the SCS process for the case of HMT use as a fuel. Indeed, in case of sufficient degree of the process' non-equilibrium, a metal phase can also be formed at $\varphi<1$ if at the initial stage of synthesis, the reduction rate of $\mathrm{NiO}$ is higher than $\mathrm{Ni}$ oxidation rate, and therefore the short process time does not allow reaching a chemical equilibrium. Peculiar features of HMT in the course of SCS were also noted in [45], where it was shown that in comparison with other types of fuels (urea, citric acid, glycine), HMT has the highest recovery valence. The HMT use at $\varphi=2$ makes it possible to reach the highest adiabatic solution combustion temperature and the highest yield of metal nickel nanoparticles. Thus formation of metal nickel nanoparticles in SCS products at $\varphi<$ 1 can be related with the application of HMT.

The increase of the metallic phase portion in the sample depending on the furnace preheating rate can be linked to the reaction temperature increase and/or to the increase in the degree of nonequilibrium of the chemical process under these conditions. The formation of the metallic nickel at $\varphi<1$ and moderate reaction temperatures is of great practical importance because, as it will be shown below, such unreduced catalyst can be used in the decomposition of methane into hydrogen and nanofibrous carbon without an additional stage of its reduction with hydrogen.

Table 2 presents data on the average sizes of crystallites of nickel oxide $L_{N i O}$ and metallic nickel $L_{N i}$ in the unreduced catalyst. We can see that the $L_{N i O}$ values are between 24.3-26.8 nm regardless of the preheating rate. The $L_{N i}$ values are much higher, 166 and $190 \mathrm{~nm}$ for samples 2 and 3, respectively. The increase in $L_{N i}$, compared to $L_{N i O}$, can be explained by a more intensive sintering of metallic nanoparticles in the SCS. The certain increase in $L_{N i}$ with an increase in $V$ could be connected to an increase in $T_{\max }$, when the $V$ increases. 


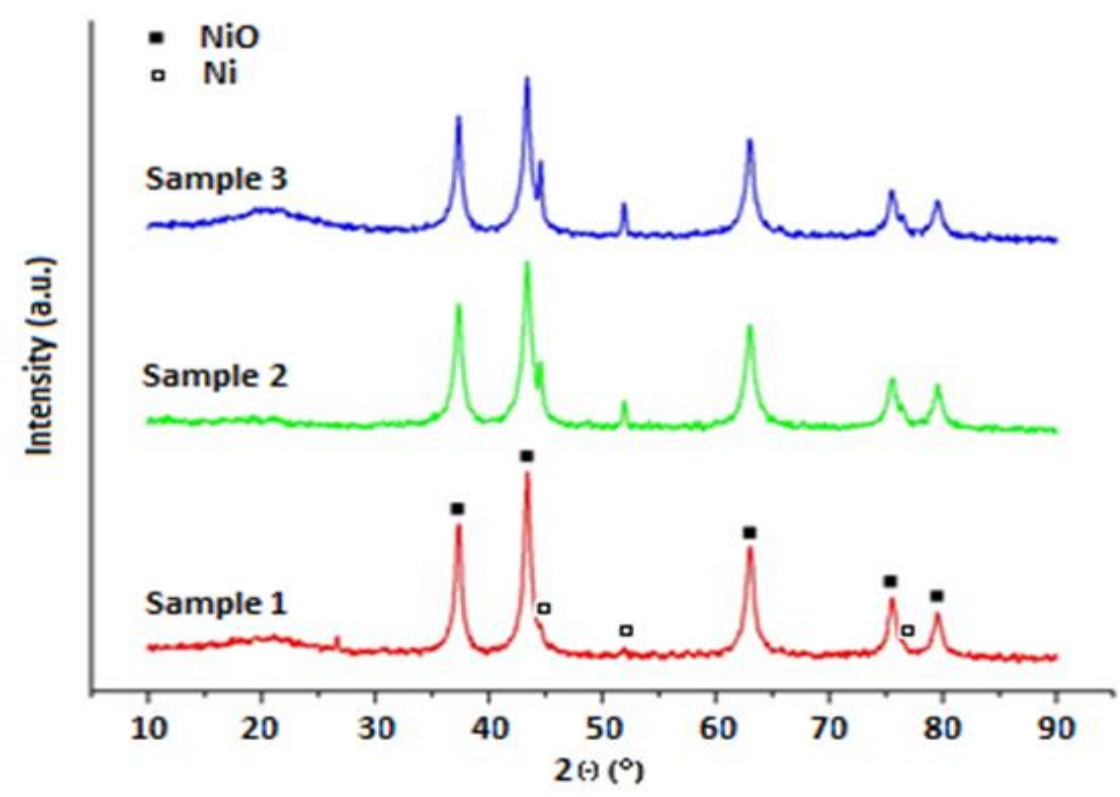

Fig. 6 - XRD patterns of unreduced catalyst samples $(\varphi=0.7)$.

Table 2. Experimental results for the $\mathrm{Ni}\left(\mathrm{NO}_{3}\right)_{2} / 0.062 \mathrm{Al}\left(\mathrm{NO}_{3}\right)_{3}-\mathrm{HMT}$ system

\begin{tabular}{|l|ccc|}
\hline \multicolumn{4}{|c|}{ Excess fuel coefficient $\varphi=0.7$} \\
\hline Number of a Sample of unreduced catalyst & 1 & 2 & 3 \\
\hline Muffle heating rate $-V, \mathrm{~K} / \mathrm{min}$ & 1 & 10 & 15 \\
Ignition temperature $-T_{1}, \mathrm{~K}$ & 432 & 433 & 415 \\
Maximum reaction product temperature $-T_{\text {max }}, \mathrm{K}$ & 743 & 769 & 846 \\
Average size of NiO crystallites $-L_{\mathrm{NiO}}, \mathrm{nm}$ & 26 & 26,8 & 24,3 \\
Average size of Ni crystallites $-L_{\mathrm{Ni}}, \mathrm{nm}$ & $* *$ & 166 & 190 \\
$y_{\mathrm{H}}, \mathrm{mol}_{\mathrm{H}_{2}} /$ mol $_{\text {cat }}$ & 701 & 648 & 818 \\
\hline$* * \mathrm{Ni}$ phase reflections are practically absent & & & \\
\hline
\end{tabular}

\section{Test the catalyst in the methane decomposition}

The preliminary experiments have shown that unreduced catalyst obtained via SCS can be used in methane decomposition to hydrogen and nanofibrous carbon just as effectively as a hydrogen reduced catalyst. Therefore, the majority of the experiments were carried out with the unreduced catalyst. The effectiveness of use the unreduced catalyst in methane decomposition can be attributed to the presence of a small amount of primary nanoparticles of metallic nickel acting in methane decomposition and correspondently hydrogen formation at the beginning of the process. Then the formed hydrogen initiates the reduction of nickel oxide particles. The reduction process of nickel oxide rapidly accelerates due to the increased concentration of hydrogen that has resulted from the increased content of metallic nickel in the catalyst. The primary nickel particles are relatively large and are most likely quickly deactivated. The reduced nickel nanoparticles have a smaller size than their primary counterparts and get saturated with carbon, which then proceeds to emerge from these particles in the form of nanofibers or nanotubes. The process then continues via the same mechanism as with the previously reduced catalyst. 
It was established that the final solid product of methane decomposition can be produced as rather stable porous carbon granules $(>1-5 \mathrm{~mm})$, which are principally composed of nanofibrous carbon (>99 wt.\%). Fig. 7a shows a TEM image of a disintegrated granule. The experimental data indicates that the transverse dimensions of the metal nanoparticles and carbon nanofibers are the same and range in size between $20-100 \mathrm{~nm}$.

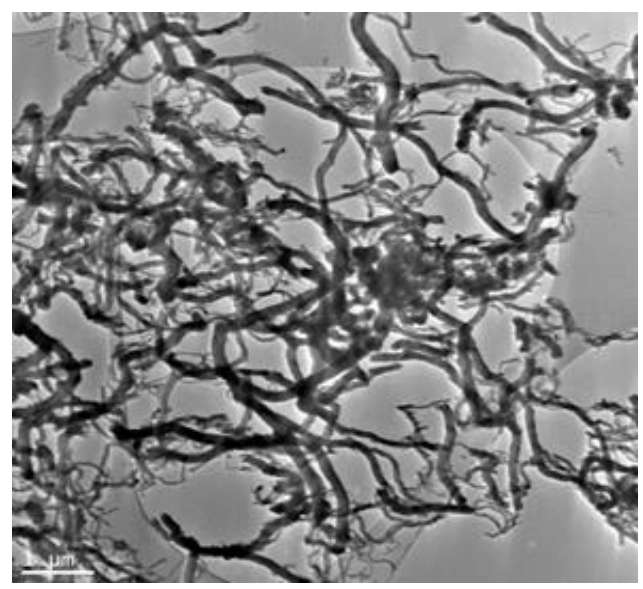

a)

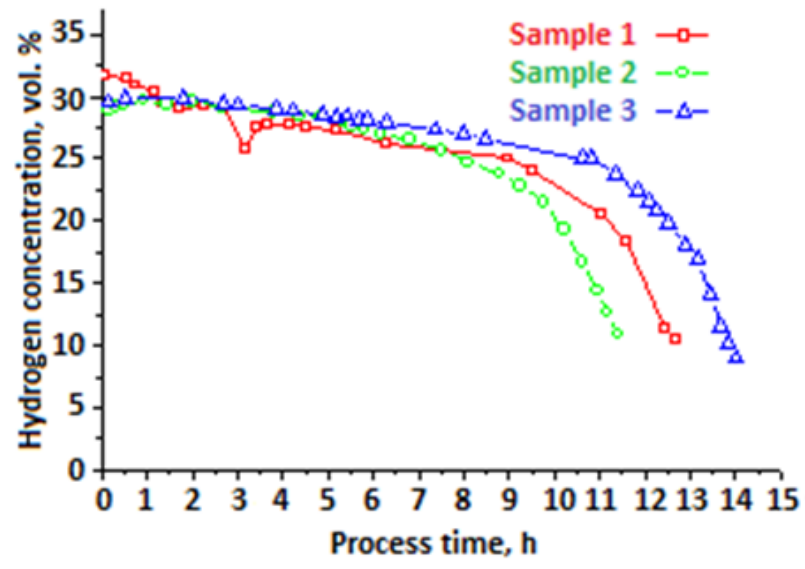

b)

Fig. 7 - SEM-image of carbon nanofibers with Ni-nanoparticles (a), and hydrogen concentration vs time in the catalytic decomposition of methane (b).

The efficiency of the unreduced catalyst usage in methane decomposition was quantified by the change in the hydrogen concentration as function of time and the specific hydrogen yield $\left(y_{H}, \mathrm{~mol}^{\mathrm{mol}} \mathrm{l}_{\mathrm{cat}}\right)$ during the catalyst deactivation period. The dependence of the hydrogen concentration in gas phase on time for samples 1-3 is shown in Fig. 7b. It can be seen for all samples the hydrogen concentration is about $30 \%$ at the beginning of the process. The timescale of the catalyst's activation is insignificant in compare to the overall live time. First, depending on the time, the concentration of hydrogen, remaining at a level above $25 \%$, slowly decreases within 7-12 hours, and then quickly falls within 2-3 hours.

On the basis of the data presented in Table 2 and Fig. $7 \mathrm{~b}$ it is possible to conclude that the maximum time of catalyst deactivation $\left(t_{2}=14 \mathrm{~h}\right)$ and the maximum specific yield of hydrogen $\left(y_{H}=818 \mathrm{~mol} \mathrm{~mol}_{\text {cat }}\right)$ were achieved using sample 3 . The sample was obtained via SCS with the highest values of $\mathrm{V}$ and $\mathrm{T}_{\max }$. It was found the sample 3 has the smallest average size of the $\mathrm{NiO}$ crystallites $\left(L_{N i O}=24.3 \mathrm{~nm}\right)$.

Table 3 provides data to compare our results to the published data related to methane decomposition into hydrogen and nanocarbon. Table 3 shows the composition of catalyst, the temperature of methane decomposition $\left(T,{ }^{\circ} \mathrm{C}\right)$, partial methane pressure at the reactor inlet $(p$, bar), methane inlet specific flow rate (MISFR, $\left.\mathrm{mol} / \mathrm{h} / \mathrm{g}_{\mathrm{cat}}\right)$, the time of relatively stable catalyst performance $\left(t_{1}, \mathrm{~h}\right)$, the time of complete catalyst deactivation $\left(t_{2}, \mathrm{~h}\right)$, average methane conversion $(X, \%)$ during the time $t_{1}$, average catalyst activity $\left(A_{X}=\operatorname{MISFR} * X / 100, \mathrm{~mol}_{\mathrm{CH} 4} / \mathrm{h} / \mathrm{g}_{\text {cat }}\right)$ during time $t_{1}$, specific yield of hydrogen, determined by the gain of carbon per unit weight of unreduced catalyst during the time $t_{2}\left(y_{H}, \mathrm{~mol} / \mathrm{mol}_{\mathrm{cat}}\right)$. The data from different publications were processed to the same respective measurement units. The 1 gram of unreduced catalyst $\left(\mathrm{g}_{\text {cat }}\right)$ was taken as a unit of catalyst mass. The following ratios were used in values recalculation: in case of pure methane supplied to the reactor entry $C_{C H 4}+C_{H}=100$ (where $C_{C H 4}, C_{H}$ are methane and 
hydrogen concentrations at the outlet, vol. $\%) ; X=C_{H} /\left(200-C_{H}\right) * 100=\left(100-C_{C H 4}\right) /$ $\left(100+C_{C H 4}\right) * 100$; the weight of unreduced $B(w t \%) N i / S i O_{2}$ - catalyst $m=m_{N i} /(B / 100) *$ $(1+16 *(B / 100) / 58,7)$, where $m_{N i}$ is Ni weight in unreduced catalyst of weight $m$. The data contained in columns 2-6 characterise the conditions of the process course, and the data in columns 7-11 characterise stability, conversion, catalyst activity and specific yield of hydrogen.

Table 3. Different authors data on testing Ni catalysts in the process of methane decomposition into hydrogen and nanocarbon

\begin{tabular}{|c|c|c|c|c|c|c|c|c|c|c|}
\hline 1 & 2 & 3 & 4 & 5 & 6 & 7 & 8 & 9 & 10 & 11 \\
\hline & Ni Catalysts* & $T$ & Inlet gas & $p$ & MISFR & $t_{1}$ & $t_{2}$ & $X$ & $A_{X}$ & $y_{H}$ \\
\hline Ref. & & ${ }^{\circ} \mathrm{C}$ & & bar & $\mathrm{mol} / \mathrm{h} / \mathrm{g}_{\text {cat }}$ & $\mathrm{h}$ & $\mathrm{h}$ & $\%$ & $\mathrm{~mol}_{\mathrm{CH}} / \mathrm{h} / \mathrm{g}_{\text {cat }}$ & $\mathrm{mol} / \mathrm{g}_{\text {cat }}$ \\
\hline [24], 1999 & $90 \mathrm{wt} \% \mathrm{Ni} / \mathrm{SiO} 2$ & 550 & pure methane & 1 & 3.87 & 30 & 39 & 19.7 & 0.765 & 45.1 \\
\hline$[20], 2003$ & $40 \mathrm{wt} \% \mathrm{Ni} / \mathrm{SiO} 2$ & 500 & pure methane & 1 & 3.62 & 50 & 70 & 7 & 0.253 & 29.5 \\
\hline [43], 2017 & unsupported $\mathrm{NiO}$ & 700 & pure methane & 1 & 0.402 & 6 & - & $\begin{array}{c}48 \\
\text { (Fig.4a) }\end{array}$ & 0.193 & - \\
\hline [52], 2018 & $55 \mathrm{wt} \% \mathrm{Ni} / 2 \mathrm{MgO} . \mathrm{Al} 2 \mathrm{O} 3$ & 600 & $\mathrm{CH}_{4}: \mathrm{N}_{2}=15 / 85$ & 0.15 & 0.321 & 6 & 10 & $\begin{array}{c}55 \\
\text { (Fig.4a) }\end{array}$ & 0.177 & $\begin{array}{c}2.47 \\
\text { (Fig.5b) }\end{array}$ \\
\hline Our data & $\mathrm{NiO} / \mathrm{SiO}_{2}$. sample3 & 550 & pure methane & 1 & 4.46 & 10 & 14 & 15.6 & 0.697 & 10.8 \\
\hline
\end{tabular}

It is well-known that in this process the stability of a catalyst decreases over a time especially fast with the rapid rise of temperature and an increase in MISFR. The same trend can be also traced in comparison of the data provided in Table 3. Unfortunately, the time $t_{1}$ in [43] was limited by 6 hours, and no data on $t_{2}$ were provided.

The lowest catalyst stability in [52] is probably caused by increased reaction temperature $(T)$, and by methane dilution with nitrogen at the reactor inlet, as was observed in the case of [17,53]. Relatively low stability of our catalyst in compare with the data of Ermakova et al. [24] and S. Takenaka et al. [20] can be explained by a relatively low content of the supporter in the catalyst and to higher MISFR in our experiments. Besides, one can assume that the achieved stability of the catalysts received by the SCS method isn't maximal and can be significantly increased by optimization of the operating parameters of SCS and the methane decomposition process.

Methane decomposition is an endothermic reaction that goes with increase in the volume of a gaseous phase, and the maximum possible conversion is determined by a chemical equilibrium. In this connection (according to the laws of thermodynamics and kinetics) methane conversion has to increase with an increase in temperature and decrease in partial pressure and MISFR. Differences between the experimental data on methane conversion provided in Table 3, including our data, meet the above-noted expectations. Maximum conversions were obtained in work [43], and [52], but those values were obtained with the lowest MISFR apparently allowing a catalyst to perform at the conditions close to chemical equilibrium. Increase in conversion at those conditions doesn't compensate the decrease in MISFR and the values of catalytic activity appear to be low. It should be noted that Takenaka et al. [20] in order to increase the stability and specific yield of reaction products performed the reaction at the lowest temperature $\left(500{ }^{\circ} \mathrm{C}\right)$. In such condition conversion was at the level of $7 \%$ which seems to be insufficient for practical applications. In our experiments conversion is at the level of one of the catalysts with the best integral characteristics [24] and can be further increased without decrease in other parameters by a decrease in the MISFR. 
As it can be seen from Table 3 the activity value of the sample 3 is $0.697 \mathrm{~mol} / \mathrm{h} / \mathrm{g}_{\text {cat }}$ and it is $10 \%$ lower in comparison with the maximum activity of $0.765 \mathrm{~mol} / \mathrm{h} / / \mathrm{g}_{\text {cat }}$ obtained in work [24] as result of active phase particles size optimization, as well as composition, structure and texture of $\mathrm{Ni} / \mathrm{SiO}_{2}$ catalyst. Relatively low activity of the Ni catalyst [43] and [52] in compare with others presented in Table 3 can be explained by significant differences in regime parameters: higher temperatures might have changed the reaction mechanism; reduced specific flow rate of methane at the reactor inlet could shift conditions close to chemical equilibrium at which the chemical reaction proceeds at low rate.

As noted above, $y_{H}$ is considered as the integral indicator of the catalyst efficiency in the process under consideration. If the MISFR is constant and the $X(t)$ is a simple functional dependence we can express $y_{H} \sim I S M C * X * t_{2}=A * t_{2}$. This shows that in order to obtain high $y_{H}$ values, it is necessary to ensure sufficiently high values of both the activity and the stability of the catalyst. From Table 3 it can be seen that the catalyst obtained by the SCS method using HMT as a fuel is somewhat inferior in term of the $y_{H}$ to the best samples presented in the scientific literature, but this is mainly due to its relatively low stability. The stability of such catalyst can be increased by an optimization of catalyst composition and operation parameters of catalyst synthesis and methane decomposition process.

\section{Conclusions}

1. A review of publications shows that development of effective metal-oxide catalyst remains one of the key problems in development of a technology for co-production of hydrogen and nanofibrous carbon via catalytic decomposition of methane. Solutions combustion synthesis (SCS) is recognised as one of the most attractive methods to prepare supported metal-oxide catalysts of complex composition in one quickly proceeding stage. Publications on synthesis and application of a catalyst prepared via SCS method using hexamethylenetetramine (HMT) as a fuel for hydrogen and nanofibrous carbon co-production are not known to a date.

2. The generalized chemical equations reflecting different ideas about combustion of $H M T-$ $\mathrm{Ni}\left(\mathrm{NO}_{3}\right)_{2}-\mathrm{Cu}\left(\mathrm{NO}_{3}\right)_{2}-\mathrm{Al}\left(\mathrm{NO}_{3}\right)_{3}-\mathrm{H}_{2} \mathrm{O}$ system have been derived in the present work. On the basis of these equations the thermodynamic numerical investigation of the adiabatic combustion temperature $\left(T_{a d}\right)$ and gaseous products volume $\left(n_{g}\right)$ depending on the accepted assumptions regarding the SCS, ignition temperature $\left(T_{1}\right)$, water content in the reaction mixture at the moment of ignition $(m)$, excess fuel coefficient $(\varphi)$ and the composition of the unreduced catalyst obtained have been performed. Calculations showed that the main parameters ensuring the change in the adiabatic temperature of the SCS in the range from hundreds to thousands of degrees Kelvin are $\varphi, m$ and $T_{1}$. At $\varphi<1$ the $T_{a d}(\varphi)$ dependence is increasing, and at $\varphi>1$ the character of $T_{a d}(\varphi)$ change depends on the value of $m$ and the variant of oxygen supply to the reaction zone. Other things being equal, the adiabatic temperature can increase by hundreds of degrees with an increase in the proportion of alumina in the catalyst and decrease by tens of degrees with an increase in the share of the metal phase in the catalyst. For the synthesis of $0.97(\mathrm{NiO}+\mathrm{CuO}) / 0.03 \mathrm{Al}_{2} \mathrm{O}_{3}$ catalyst at the conditions of $T_{1}=423 \mathrm{~K}, \varphi=1, \mathrm{~m}=1.5 \mathrm{~mol} /$ $\mathrm{mol}_{\text {cat }}$ the calculation gives $n_{g}=6.69 \frac{\mathrm{mol}}{\mathrm{mol}_{\text {cat }}}, T_{a d} \approx 2930 \mathrm{~K}, \Delta T_{a d} \approx(0.6 \div 0.65) \Delta T_{1}$.

3. The experimental studies of synthesis of $\mathrm{NiO} / \mathrm{Al}_{2} \mathrm{O}_{3}$ catalyst by SCS method carried out at the constant heating rates $\left(V_{n}=1 \div 15 \mathrm{~K} / \mathrm{min}\right)$ and the fuel excess coefficient of $\varphi=0.7$ have shown that self-ignition temperature of the reaction mixture does not depend on the heating rate and is 
about $430 \mathrm{~K}$. The highest combustion temperature $\left(T_{\max }=846 \mathrm{~K}\right.$ at $\left.V_{n}=15 \mathrm{~K} / \mathrm{min}\right)$ turned out to be much lower than the calculated adiabatic combustion temperature. The difference between $T_{a d}$ and $T_{\max }$ can be caused by temperature losses taking place at laboratory conditions. The obtained finely-dispersed solid product (unreduced catalyst) consisted mostly of nickel oxide nanoparticles with the average crystallite size of $L_{N i O}=24-27 \mathrm{~nm}$, alumina and relatively small amount of metallic nickel particles with a crystallite size of $L_{N i}=166-190 \mathrm{~nm}$. Appearance of metal nickel at $\varphi<1$ contradicts the equilibrium thermodynamics and the earlier published experimental data obtained using other types of fuel, therefore it is possible to conclude that a metal nickel phase formation at $\varphi<1$ happens due to the fact that use of HMT in the course of SCS causes the significant increase in the degree of non-equilibrium of the process. Indeed, in non-equilibrium conditions the metal phase can be formed at $\varphi<1$, if, for example, the reduction rate of nickel oxide by intermediate products at the initial stage of synthesis is higher than the oxidation rate of metal nickel, and short process time and rapid cooling of solid products do not allow changes in the ratio of those rates and reaching a chemical equilibrium.

4. Use of HMT in the course of SCS at $\varphi<1$ makes it possible to obtain unreduced $0.97 \mathrm{NiO} / 0.03 \mathrm{Al}_{2} \mathrm{O}_{3}$ catalyst which shows high performance in the course of methane decomposition into hydrogen and nanofibrous carbon and does not require preliminary reduction by hydrogen. The results of testing unreduced catalyst samples in a methane decomposition reaction at temperature $823 \mathrm{~K}$, methane inlet specific flow rate $100 \mathrm{~L} / \mathrm{mol} / \mathrm{g}_{\text {cat }}$, and pressure $1 \mathrm{bar}$ have shown that specific hydrogen yield during the period of catalyst deactivation $\left(y_{H}\right)$ can reach $818 \mathrm{~mol} / \mathrm{mol}_{\text {cat }}$, and its activity $\left(0.7 \mathrm{~L} / \mathrm{mol} / \mathrm{g}_{\text {cat }}\right)$ reaches maximum activity levels of catalysts preliminarily reduced in hydrogen flow, reported in articles published so far. The ability of unreduced catalyst obtained in the conditions of fuel shortage to self-activate in a flow of methane can be explained by the presence of metal nickel nanoparticles in the SCS products that are formed in the course of SCS when hexamethylenetetramine is used as a fuel.

Thus, the results of this work show that SCS using HMT as a fuel is an attractive way to create a large-scale technology to prepare Ni catalysts for the process of methane decomposition into hydrogen and nanofibrous carbon.

Further studies on concerning creation of this type of Ni catalysts should aim to increase stability and specific yield of hydrogen based on optimization of the composition, structure and texture of the catalyst, as well as the operation parameters of catalyst synthesis and methane decomposition process.

\section{Acknowledgment}

This work was partially supported by the Russian President's Scholarship Fund (grant SP69.2016).

\section{References}

[1] Muradov NZ. How to produce hydrogen form fossil fuels without CO2 emission. Int J Hydrogen Energy 1993;18:211-5.

[2] Muradov NZ. CO2 -Free Production of Hydrogen by Catalytic Pyrolysis of Hydrocarbon Fuel. Energy \& Fuels 1998;12:41-8. doi:10.1021/ef9701145.

[3] Kuvshinov GG, Mogilnykh YI, Kuvshinov DG, Zavarukhin SG, Parmon VN. New ecologically sound technology to produce hydrogen and new carbon material via low temperature catalytic pyrolysis. Proc. 11th World Hydrog. Energy Conf. 23-28 June., 
Stuttgart, Germany: 1996, p. 655-60.

[4] Li Y, Li D, Wang G. Methane decomposition to COx-free hydrogen and nano-carbon material on group 8-10 base metal catalysts: A review. Catal Today 2011;162:1-48. doi:10.1016/j.cattod.2010.12.042.

[5] Kuvshinov GG, Mogilnykh YI, Kuvshinov DG, Yermakov DY, Yermakova MA, Salanov AN, et al. Mechanism of porous filamentous carbon granule formation on catalytic hydrocarbon decomposition. Carbon N Y 1999;37. doi:10.1016/S00086223(98)00320-0.

[6] Su DS, Centi G. A perspective on carbon materials for future energy application. J Energy Chem 2013;22:151-73. doi:10.1016/S2095-4956(13)60022-4.

[7] Serp P, Corrias M, Kalck P. Carbon nanotubes and nanofibers in catalysis. Appl Catal A Gen 2003;253:337-58. doi:10.1016/S0926-860X(03)00549-0.

[8] Shinkarev VV, Glushenkov AM, Kuvshinov DG, Kuvshinov GG. Nanofibrous carbon with herringbone structure as an effective catalyst of the H2S selective oxidation. Carbon N Y 2010;48. doi:10.1016/j.carbon.2010.02.008.

[9] Fenelonov VB, Avdeeva LB, Zeyvot VI, Okkel LG, Goncharova OV, Pimneva LG. Texture and adsorption properties of fibrous carbon obtained by decomposition of carbon-containing gases on metal catalysts. Kinet Katalis 1993;34:545-9.

[10] Smith SC, Rodrigues DF. Carbon-based nanomaterials for removal of chemical and biological contaminants from water: A review of mechanisms and applications. Carbon N Y 2015;91:122-43. doi:10.1016/j.carbon.2015.04.043.

[11] Kovalenko GA, Kuznetsova E V., Mogilnykh YI, Andreeva IS, Kuvshinov DG, Rudina NA. Catalytic filamentous carbons for immobilization of biologically active substances and non-growing bacterial cells. Carbon N Y 2001;39:1033-43. doi:10.1016/S0008-6223(00)00216-5.

[12] Tibbets G, Lake M, Strong K, Rice B. A review of the fabrication and properties of vapor-grown carbon nanofiber/polymer composites. Compos Sci Technol 2007;67:1709-18. doi:10.1016/j.compscitech.2006.06.015.

[13] Bannov AG, Uvarov NF, Shilovskaya SM, Kuvshinov GG. Effect of the preparation methods on electrical properties of epoxy resin/carbon nanofiber composites. Nanotechnologies Russ 2012;7:169-77. doi:10.1134/S1995078012020048.

[14] Kuvshinov GG, Avdeeva LB, Goncharova OV, Mogilnykh YI. Peculiarities of the Process of Producing of Carbon Materials of Fibrous Structure and Hydrogen by Hydrocarbon Decomposition in Instatic Catalyst Bed Reactor. Proc. Achema-94, Frankfurt-am-Main, Frankfurt-Am-Main: 1994, p. 9.6.

[15] Kuvshinov GG. Environmentally sound nontraditional processing of hydrocarbon energy carriers to produce and use hydrogen. Proc. Third Int. Conf. New Energy Syst. Conversions, Kazan, Kazan, Russia.: 1997, p. 47-51.

[16] Kuvshinov GG, Zavarukhin SG, Mogilnykh YI, Kuvshinov DG. The realization of the process for the production of granular catalytic filamentous carbon in the pilot reactor scale. Khimicheskaya Promishlennost (Rus) 1998:300-7.

[17] Kuvshinov GG, Popov MV, Tonkodubov SE, Kuvshinov DG. Effect of pressure on the efficiency of nickel and nickel-copper catalysts in decomposition of methane. Russ J Appl Chem 2016;89. doi:10.1134/S1070427216110070.

[18] Kuvshinov GG, Popov MV, Soloviev EA, Arzumanyan AI, Peshkov GA. Non-traditional Process of Hydrogen Containing Fuel Mixtures Production for Internal-combustion Engines. Eur Res 2012;36:2102-13.

[19] Dupuis AC. The catalyst in the CCVD of carbon nanotubes-a review. Prog Mater Sci 2005;50:929-61. doi:10.1016/j.pmatsci.2005.04.003.

[20] Takenaka S, Kobayashi S, Ogihara H, Otsuka K. Ni/SiO2 catalyst effective for methane decomposition into hydrogen and carbon nanofiber. J Catal 2003;217:79-87. 
doi:10.1016/S0021-9517(02)00185-9.

[21] Rastegarpanah A, Meshkani F, Rezaei M. CO x -free hydrogen and carbon nano fi bers production by thermocatalytic decomposition of methane over mesoporous $\mathrm{MgO} \cdot \mathrm{Al}$ 203 nanopowder-supported nickel catalysts. Fuel Process Technol 2017;167:25062. doi:10.1016/j.fuproc.2017.07.010.

[22] Rastegarpanah A, Meshkani F, Rezaei M. Thermocatalytic decomposition of methane over mesoporous nanocrystalline promoted $\mathrm{Ni} / \mathrm{MgO} \cdot \mathrm{Al} 2 \mathrm{O} 3$ catalysts. Int J Hydrogen Energy 2017;42:16476-88. doi:10.1016/j.ijhydene.2017.05.044.

[23] Pudukudy M, Kadier A, Yaakob Z, Takriff MS. Non-oxidative thermocatalytic decomposition of methane into $\mathrm{COx}$ free hydrogen and nanocarbon over unsupported porous $\mathrm{NiO}$ and Fe2O3 catalysts. Int J Hydrogen Energy 2016;41:18509-21. doi:10.1016/j.ijhydene.2016.08.160.

[24] Ermakova MA, Ermakov DY, Kuvshinov GG, Plyasova LM. New nickel catalysts for the formation of filamentous carbon in the reaction of methane decomposition. J Catal 1999;187:77-84. doi:10.1006/jcat.1999.2562.

[25] Kuvshinov GG, Mogilnykh YI, Kuvshinov DG, Zaikovskii VI, Avdeeva LB. Peculiarities of filamentous carbon formation in methane decomposition on ni-containing catalysts. Carbon N Y 1998;36:87-97.

[26] Pudukudy M, Yaakob Z, Takriff MS. Methane decomposition into COx free hydrogen and multiwalled carbon nanotubes over ceria, zirconia and lanthana supported nickel catalysts prepared via a facile solid state citrate fusion method. Energy Convers Manag 2016;126. doi:10.1016/j.enconman.2016.08.006.

[27] Wang HY, Lua AC. Methane decomposition using Ni-Cu alloy nano-particle catalysts and catalyst deactivation studies. Chem Eng J 2015;262:1077-89. doi:10.1016/j.cej.2014.10.063.

[28] Ermakova MA, Ermakov DY, Kuvshinov GG. Effective catalysts for direct cracking of methane to produce hydrogen and filamentous carbon. Part I. Nickel catalysts. Appl Catal A Gen 2000;201. doi:10.1016/S0926-860X(00)00433-6.

[29] Reshetenko T V., Avdeeva LB, Ismagilov ZR, Chuvilin AL, Ushakov VA. Carbon capacious $\mathrm{Ni}-\mathrm{Cu}-\mathrm{Al} 203$ catalysts for high-temperature methane decomposition. Appl Catal A Gen 2003;247:51-63. doi:10.1016/S0926-860X(03)00080-2.

[30] Chai S-P, Mohamed AR. Catalyzed Decomposition of Methane into COx-free Hydrogen and Filamentous Carbons over NiO-CuO/SiO2: Effect of NiO-CuO Loadings. Int J Chem React Eng 2010;8:1-13.

[31] Shen Y, Lua AC. Sol-gel synthesis of titanium oxide supported nickel catalysts for hydrogen and carbon production by methane decomposition. J Power Sources 2015;280:467-75. doi:10.1016/j.jpowsour.2015.01.057.

[32] Chesnokov V V., Chichkan AS. Production of hydrogen by methane catalytic decomposition over Ni-Cu-Fe/Al2O3 catalyst. Int J Hydrogen Energy 2009;34:297985. doi:10.1016/j.ijhydene.2009.01.074.

[33] Dinka P, Mukasayan A. In situ preparation of Oxide-based Supported Catalysts by Solution Combustion Synthesis. J Phys Chem B 2005;109:21627-33.

[34] Smagulova GT, Mansurov ZA, Prikhod'ko NG, Mironenko A V, Zakhidov AA, Mansurov NB. Synthesis of carbon nanotubes on catalysts prepared by solution combustion on glass-fibers. Proceeding Eur. Combust. Meet. Budapest, 2015, p. 117-8.

[35] Kingsley JJ, Patil KC. NOVEL COMBUSTION PROCESS FOR THE SYNTHESIS OF FINE PARTICLE. Mater Lett 1988;6:427-32.

[36] Nersisyan HH, Lee JH, Ding JR, Kim KS, Manukyan K V., Mukasyan AS. Combustion synthesis of zero-, one-, two- and three-dimensional nanostructures: Current trends and future perspectives. Prog Energy Combust Sci 2017;63:79-118. doi:10.1016/j.pecs.2017.07.002. 
[37] Varma A, Mukasyan AS, Rogachev AS, Manukyan K V. Solution Combustion Synthesis of Nanoscale Materials. Chem Rev 2016;116:14493-586.

doi:10.1021/acs.chemrev.6b00279.

[38] González-Cortés SL, Imbert FE. Fundamentals , properties and applications of solid catalysts prepared by solution combustion synthesis ( SCS ). "Applied Catal A Gen 2013;452:117-31. doi:10.1016/j.apcata.2012.11.024.

[39] Dumitrescu AM, Samoila PM, Nica V, Doroftei F, Iordan AR, Palamaru MN. Study of the chelating/fuel agents influence on NiFe204 samples with potential catalytic properties. Powder Technol 2013;243:9-17. doi:10.1016/j.powtec.2013.03.033.

[40] Samantaray S, Mishra BG, Pradhan DK, Hota G. Solution combustion synthesis and physicochemical characterization of $\mathrm{ZrO} 2-\mathrm{MoO} 3$ nanocomposite oxides prepared using different fuels. Ceram Int 2011;37:3101-8.

doi:10.1016/j.ceramint.2011.05.047.

[41] Prakash AS, Khadar AMA, Patil KC, Hegde MS. Hexamethylenetetramine: A new fuel for solution combustion synthesis of complex metal oxides. J Mater Synth Process 2002;10:135-41. doi:10.1023/A:1021986613158.

[42] Rakov EG, Blinov SN, Ivanov IG, Rakova E V., Digurov NG. Continuous Process for Obtaining Carbon Nanofibers. Russ J Appl Chem 2004;77:187-191.

[43] Pudukudy M, Yaakob Z. Production of COx Free Hydrogen and Nanocarbon via Methane Decomposition Over Unsupported Porous Nickel and Iron Catalysts. J Clust Sci 2017. doi:10.1007/s10876-017-1173-5.

[44] Tkachev AG, Ribkin SV. Determination of the composition and method for the preparation of a catalyst for the synthesis of carbon nanostructured materials. Vopr Sovrem Nauk i Prakt 2007;2:166-74.

[45] Khort A, Podbolotov K, Serrano-García R, Gun'ko YK. One-step solution combustion synthesis of pure Ni nanopowders with enhanced coercivity: The fuel effect. J Solid State Chem 2017;253:270-6. doi:10.1016/j.jssc.2017.05.043.

[46] Knunyants IL, editor. Chemicheskaya enciklopediya (Rus), v.1. Moscow: 1988.

[47] Nikolsky BP, editor. Spravochik Khimika, v.1, 2nd edition (Rus). Moscow: Khimiya; 1966.

[48] Yurchenko GO, Butenko AM, Loboyko VA, Kobzev AV. Analysis of the thermodynamic characteristics of the process recovery of nickel recycled. Eastern-European J Enterp Technol 2012;6:35-40.

[49] https://www.chemeo.com/cid/14-126-6/Hexamethylenetetramine\#ref-nistwebbook. n.d.

[50] Manukyan K V., Cross A, Roslyakov S, Rouvimov S, Rogachev AS, Wolf EE, et al. Solution Combustion Synthesis of Nano-Crystalline Metallic Materials: Mechanistic Studies. J Phys Chem C 2013;117:24417-27. doi:10.1021/jp408260m.

[51] Chernavskii PA, Afanas P V, Pankina G V, Perov NS. Formation of Co Nanoparticles in the Process of Thermal Decomposition of the Cobalt Complex with Hexamethylenetetramine ( NO 3 ) 2 Co ( H 20 ) 6 ( HMTA) 2 4 ( H 20 ). Russ J Phys Chem A 2008;82:2176-81. doi:10.1134/S0036024408130049.

[52] Rastegarpanah A, Rezaei M, Meshkani F, Dai H, Arandiyan H. Thermocatalytic decomposition of methane over mesoporous $\mathrm{Ni} / \mathrm{xMgO} \cdot \mathrm{Al} 2 \mathrm{O} 3$ nanocatalysts. Int J Hydrogen Energy 2018;43:15112-23. doi:10.1016/j.ijhydene.2018.06.057.

[53] Kuvshinov GG, Kuvshinov DG, Glushenkov AM. The Influence of Inert Impurities on the Catalyst Lifetime and Properties of Nanofibrous Carbon Produced by Utilization of Diluted Hydrocarbon Gases. Chem Sust Dev 2003;11:135-40. 